\title{
CIK1: a developmentally regulated spindle pole body-associated protein important for microtubule functions in Saccharomyces cerevisiae
}

\author{
Barbara D. Page and Michael Snyder \\ Department of Biology, Yale University, New Haven, Connecticut 06511 USA
}

\begin{abstract}
A genetic screen was devised to identify genes important for spindle pole body (SPB) and/or microtubule functions. Four mutants defective in both nuclear fusion (karyogamy) and chromosome maintenance were isolated; these mutants termed cik (for chromosome instability and karyogamy) define three complementation groups. The CIK1 gene was cloned and characterized. Sequence analysis of the CIK1 gene predicts that the CIK1 protein is 594 amino acids in length and possesses a central 300-amino-acid coiled-coil domain. Two different CIK1- $\beta$-galactosidase fusions localize to the SPB region in vegetative cells, and antibodies against the authentic protein detect CIK1 in the SPB region of $\alpha$-factor-treated cells. Evaluation of cells deleted for CIK1 (cik1-A) indicates that CIK1 is important for the formation or maintenance of a spindle apparatus. Longer and slightly more microtubule bundles are visible in cik1-A strains than in wild type. Thus, CIK1 encodes a SPB-associated component that is important for proper organization of microtubule arrays and the establishment of a spindle during vegetative growth. Furthermore, the CIK1 gene is essential for karyogamy, and the level of the CIK1 protein at the SPB appears to be dramatically induced by $\alpha$-factor treatment. These results indicate that molecular changes occur at the microtubule-organizing center (MTOC) as the yeast cell prepares for karyogamy and imply that specialization of the MTOC or its associated microtubules occurs in preparation for particular microtubule functions in the yeast life cycle.
\end{abstract}

[Key Words: Saccharomyces cerevisiae; spindle pole body; microtubule function; CIK1 gene; chromosome segregation; karyogamy]

Received March 5, 1992; revised version accepted May 21, 1992.

Many vital cellular processes, including mitosis, intracellular transport, cell motility, and morphogenesis, depend on the presence of a functional microtubule network. The microtubule-organizing center (MTOC) is essential for nucleating microtubule assembly, thereby establishing the microtubule array (Brinkley 1985). The MTOC of Saccharomyces cerevisiae is called the spindle pole body (SPB) and is analogous to the centrosome of multicellular eukaryotes. The SPB is a trilaminar complex embedded in the nuclear envelope, where it functions to organize both nuclear and cytoplasmic microtubule arrays (Byers and Goetsch 1973, 1975; Byers 1981). The association of the SPB with the nuclear envelope is maintained throughout the cell cycle, since in yeast the nuclear envelope does not break down during mitosis. In vegetatively growing cells, the SPB undergoes distinct cytological changes during its duplication process (Baum et al. 1986, 1988; Winey et al. 1991). Morphological modifications also occur during mating and meiosis (Moens and Rapport 1971; Byers and Goetsch 1975).

In yeast the SPB and its associated microtubules participate in a variety of cellular processes throughout the cell cycle and life cycle (Byers and Goetsch 1975; Peterson and Ris 1976; Byers 1981; Adams and Pringle 1984; Snyder et al. 1991). Studies using conditional tubulin mutants and microtubule-depolymerizing drugs have demonstrated that microtubules are necessary for many cellular processes in vegetative cells, including SPB orientation toward the bud, nuclear migration, establishment and maintenance of a spindle apparatus, and chromosome segregation (Delgado and Conde 1984; Huffaker et al. 1988; Jacobs et al. 1988). Microtubules are also important for nuclear fusion during mating (Delgado and Conde 1984; Huffaker et al. 1988). During conjugation, two mating cells interact and undergo a series of events that result in the formation of a zygote (Cross et al. 1988). Localized cell wall breakdown allows cytoplasmic fusion and formation a transient heterokaryon that contains cytoplasmic markers of both parents and the two parental nuclei. Formation of a heterokaryon is followed by karyogamy, the process by which the two parental nuclei fuse. After cytoplasmic fusion, the two SPBs face one another, and the cytoplasmic microtubules emanating from them interdigitate. These microtubules shorten 
in length as the SPBs approach one another, and the initial nuclear contact and fusion events occur at the SPBs (Byers and Goetsch 1975; Rose 1991).

In an effort to understand SPB and microtubule-mediated processes, focus has been placed on discovering proteins that are components of the SPB or interact with microtubules, or both. To identify such components, different approaches have been used, including isolation of the SPB by cell fractionation (Rout and Kilmartin 1990), purification of microtubules and proteins that bind to them (Pillus and Solomon 1986; Barnes et al. 1992), and the use of nucleic acid or antibody probes that recognize conserved genes or components (Neff et al. 1983; Snyder and Davis 1988). These approaches have successfully identified a limited number of proteins and genes important for SPB and microtubule function.

Another approach is to identify mutations that disrupt cellular processes requiring microtubules (Hoyt et al. 1990; Spencer et al. 1990; Stearns et al. 1990). In principle, mutants defective in chromosome maintenance might be expected to identify components important for SPB and microtubule functions; however, chromosome maintenance mutants probably constitute a broad class. Enhanced chromosome loss has been found in mutants deficient in a variety of cellular processes, including nucleotide metabolism, DNA replication, disentanglement of sister chromatids, or coordination of the cell cycle (Hartwell and Smith 1985; Holm et al. 1985; Weinert and Hartwell 1988; Hoyt et al. 1991; Rong and Murray 1991). Thus, mutants important for SPB and microtubule function are likely to comprise a small subset of those exhibiting chromosome maintenance defects. Mutants defective in karyogamy have also been isolated through assorted screens (Conde and Fink 1976; Poliana and Conde 1982; Kim et al. 1991). KAR3 (a kinesin homolog) participates in microtubule function, and KAR1 plays a role in SPB function (Rose and Fink 1987; Meluh and Rose 1990; Vallen et al. 1992). The role of KAR2 in microtubule and/or SPB function may be indirect; KAR2 encodes a BIP1 homolog and localizes to the endoplasmic reticulum (Rose et al. 1989). Therefore, karyogamy screens probably also identify genes involved in a variety of cellular processes.

To restrict our analysis to genes that are likely to be important for SPB and microtubule function, we sought mutants defective in both chromosome maintenance and karyogamy. Several mutants, such as kar3-1, bik1-1, and spa1-1, were isolated by other methods and have been shown to be defective in both processes. BIK1 and KAR3 colocalize with microtubules, and SPA1 is associated with the SPB (Snyder and Davis 1988; Berlin et al. 1990; Meluh and Rose 1990). This evidence indicates that a large-scale search for mutants defective in both of these processes is likely to be successful, yet such a search has not been performed previously.

This describes a genetic screen for mutants defective in chromosome transmission and karyogamy and the identification of three genes important for these processes. One of these genes, termed CIK1 for chromosome instability and karyogamy, encodes a protein that local- izes to the SPB region. From genetic and cytological analysis, we infer that CIK1 is important for mitosis and microtubule organization. The CIK1 protein is induced by mating pheromone and is essential for karyogamy.

\section{Results}

\section{Identification of yeast mutants important} for chromosome maintenance and karyogamy

In an effort to discover genes that encode components important for SPB and microtubule functions, a screen was devised that combines the selection of karyogamy mutants and the search for mutants exhibiting a high frequency of chromosome loss (Fig. 1). The identification of karyogamy mutants relies on the ability to distinguish between the progeny of a successful karyogamy eventdiploids-and the progeny of an unsuccessful karyogamy event-cytoductants (Conde and Fink 1976). As described above, during wild-type matings, heterokaryon formation is quickly followed by nuclear fusion; however, if karyogamy is defective, the heterokaryon pro-

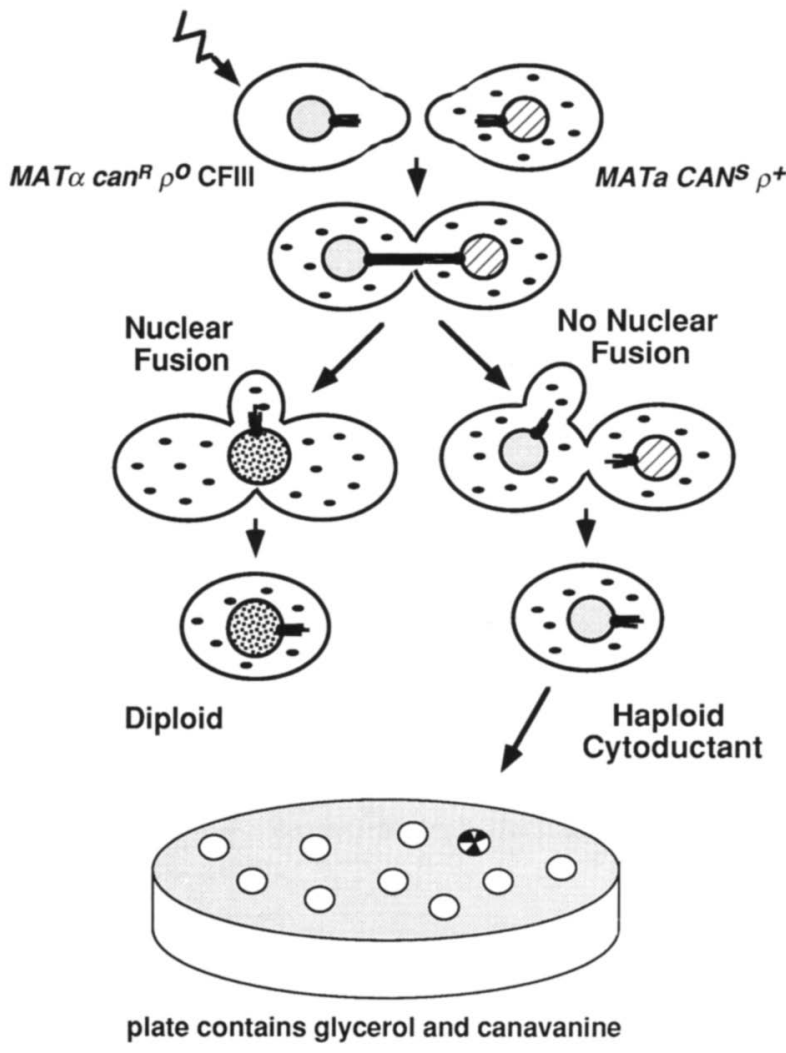

Figure 1. Diagram representing the screen for mutants defective in karyogamy and chromosome maintenance. The mutated strain (Y1009) is mated to the appropriate wild-type tester strain (Y1010). After a time sufficient for cell fusion to occur, the mating mixture is plated onto medium that selects for cytoductants containing the mutated parental genome. The plates are screened by the colony color assay for colonies that show increased loss of the dispensable chromosome derivative. 
ceeds with cell division and forms haploid progeny called cytoductants that contain the nuclear genome of only one parent and cytoplasmic markers of both. Thus, with appropriate nuclear and cytoplasmic markers, a cytoductant can be distinguished from a diploid and the parental strains. The severity of the karyogamy defect can be quantitated by evaluating the cytoductant/diploid ratio. Chromosome stability can be assessed in yeast by the loss of a dispensable chromosome containing a visible marker (Hieter et al. 1985).

A yeast strain was constructed with the following features: $\mathrm{can}^{R}, \rho^{0}$, ade2-101 and a dispensable 150-kb chromosome III derivative (CFIII) containing SUP11. $\mathrm{can}^{R}$ is a recessive nuclear mutation and confers resistance to the drug canavanine. $\rho^{0}$ strains lack mitochondrial DNA and fail to grow on plates containing glycerol as the only carbon source. When this strain is mated to a $C A N^{S} \rho^{+}$ strain $\left(\rho^{+}\right.$strains contain functional mitochondria), cytoductants containing the $c a n^{R}$ genome can be selected on glycerol plates containing canavanine. ade2-101 is an ochre mutation that results in the formation of red colonies. SUP11 is an ochre-suppressing tRNA; in the presence of SUP11, ade2-101 strains form white colonies (Hieter et al. 1985). Thus, loss of the chromosome III derivative can be detected by the appearance of red sectors in a white colony (Spencer et al. 1988, 1990). The chromosome derivative was designed such that loss of the SUP11 marker is expected to represent loss of the entire chromosome and not loss of the marker through recombination events (Spencer et al. 1990).

The $c a n^{R}, \rho^{0}$, ade2-101 strain containing the chromosome III derivative was mutagenized and mated to a "tester strain" (see Materials and methods). The mating mixture was transferred to plates that simultaneously select cytoductants and allow the identification of sectored colonies that lost the dispensable chromosome III derivative at a high frequency. After retesting karyogamy and chromosome stability phenotypes, 13 mutants were identified that exhibited a significant karyogamy defect (see Materials and methods) and a high-frequency loss of the chromosome III derivative. Of these 13 mutants, 4 failed to form colonies at $37^{\circ} \mathrm{C}$ and were analyzed further. Genetic analysis of three mutants revealed that the karyogamy, chromosome instability, and temperaturesensitive growth defects were the result of a single mutation. The fourth mutant (cik3-1; see below) could not be analyzed because heterozygotes, when sporulated, did not form viable spores; however, this mutant proved interesting for reasons to be noted elsewhere.

The chromosome instability and temperature-sensitive growth defects were recessive for three mutants and semidominant for one (cik3-1). Complementation analysis revealed that these four mutants fall into three complementation groups: CIK1,CIK2, and CIK3. cik1-1 and cik1-2, two independent alleles of CIK1, were isolated. The instability of the chromosome III derivative in each of the four $\mathrm{cik}^{-}$mutants is demonstrated by their sectoring phenotypes (Fig. 2). Quantitation of the chromosome stability and karyogamy phenotypes of cik1-1 and cik $1-2$ is presented with analysis of the cik1- $\Delta 3$ null mutation described below; further description of cik2-1 and cik3-1 will be presented elsewhere.

\section{Isolation and sequence analysis of the CIKl gene}

The CIK1 gene was cloned by complementation of the cik1-2 temperature-sensitive phenotype (details in Materials and methods). Subcloning analysis revealed a 3.6-kb region that fully complemented the karyogamy, chromosome instability, and temperature-sensitive phenotypes of both cik1-1 and cik1-2. Genetic analysis revealed that the complementing DNA is tightly linked to

Figure 2. The chromosome derivative loss phenotype for cik1-1 (Y1060), cik1-2 (Y1128), cik2-1 (Y1072), cik3-1 (Y1021), and wild-type (Y1008) strains at $25^{\circ} \mathrm{C}$.

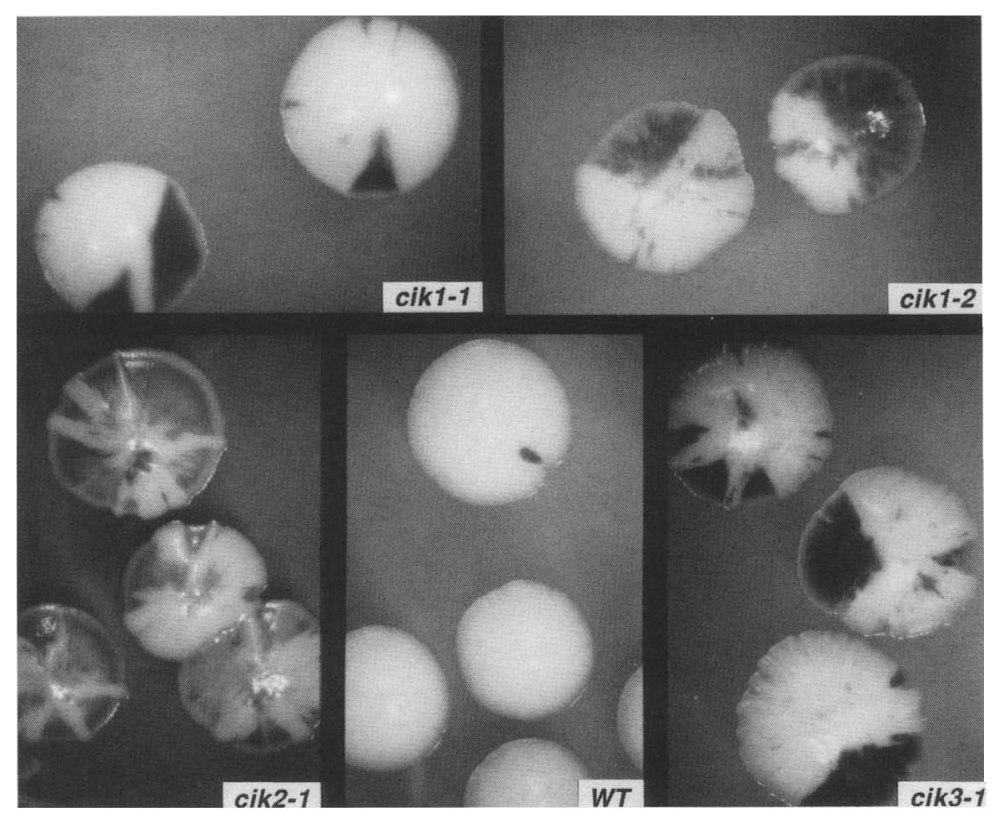


the CIK1 gene (details in Materials and methods). Gelblot analysis of genomic DNA indicated that CIK1 is a single-copy gene (not shown). The CIK1 gene was mapped to chromosome XIII by hybridization to yeast chromosomal DNA separated in a pulsed-field gel (Carle and Olson 1985) (not shown).

In an attempt to learn more about the function and structure of the CIK1 protein, the DNA sequence of the 3.6-kb region containing the CIK1 gene was determined (Fig. 3). This sequence contains a single large open read- ing frame extending $1782 \mathrm{bp}$, which is capable of encoding a protein 594 amino acids in length. The predicted size of the resulting protein is $71 \mathrm{kD}$, in close agreement with the $77-\mathrm{kD}$ molecular mass determined by immunoblot analysis (see below).

The predicted CIK 1 protein sequence was compared with sequences in the GenBank data base using the tFASTA program (Pearson 1990). Although the CIK1 protein sequence is not closely related to any other sequence in the data base, a large central domain (residues

-1329 catagaatatttaattgcagtagtttttatcagtaaggtagcgttgatattactagtgaaggtaactctatagttccttgacatgttctttagattctagaggttttt tattgaattt -1210 gttt.cccaccttatttaaactttgagaacaaaactagcaaagrcaataatataaggactgcgataatggcatagcttatgaatttattagcaactagccttctagtcattgtttttag -1091 tgtcttatactttatccacatatgaatccgcttgaaacaaggtctgtcttgcattttccaaagtt ctctctgtgaccttaaatccatcattatttgtgaccctattccttcagttt -972 catttgctattctactggcatcttttagtctatctcccgatttctgtaagattgcatggttgctcaacaactgttgcctttggtcatcgtcaatattagatgcgttaagatctccaaaa -853 agtctatcacgatcgcctgagtctactaaggattgcagtggtcgtttgatatcgctctgtatagtcttcttccattctcttaact tcgccttgtacgtagcacgttctgagcatcgcct -734 atgctgttattaacttctacatccatctgatctagcaggtcaacaactcatcttgttgctgttctacgtgcttcagtgtagtatttctctgtgataacggttgtgagggggcctctgc -615 taagctcgctt.ggcttgttctaaggttgtttgaagtcagattcgtatgatat aatagggaactcatagtaagccatgcagcaatgtaaagagtgcggt tgattcgttt tatacaac -496 ttaatgtaaagcttacactttccaagaatagtaattgccctatatagcacgactactccactcctaacttcattgaaattagacagtcatgtgatcagtaatatcgtccatagtg -377 atatttgtttgtttaccatttttgttcttatttactctctaatatgattctagtatatgaaagataccactgtcgtagctcgtatcaaaataaaactagtcagtcgttgaccattgagc -258 atatcgtccgagaataaggctt tactgtattatttttgatatccacacgttattgagctcattcactgatcgacacatt taggcggcttttccgtt ggctgaagcaactttgaaaca -139 caactacgacattataattaagcgcctaaataagtgaattttgtgccatagggttggaccgtgtatatataagagctattcactattttaatatttgtttggcatttgaaactcgttg -20 acatagcttattattagg

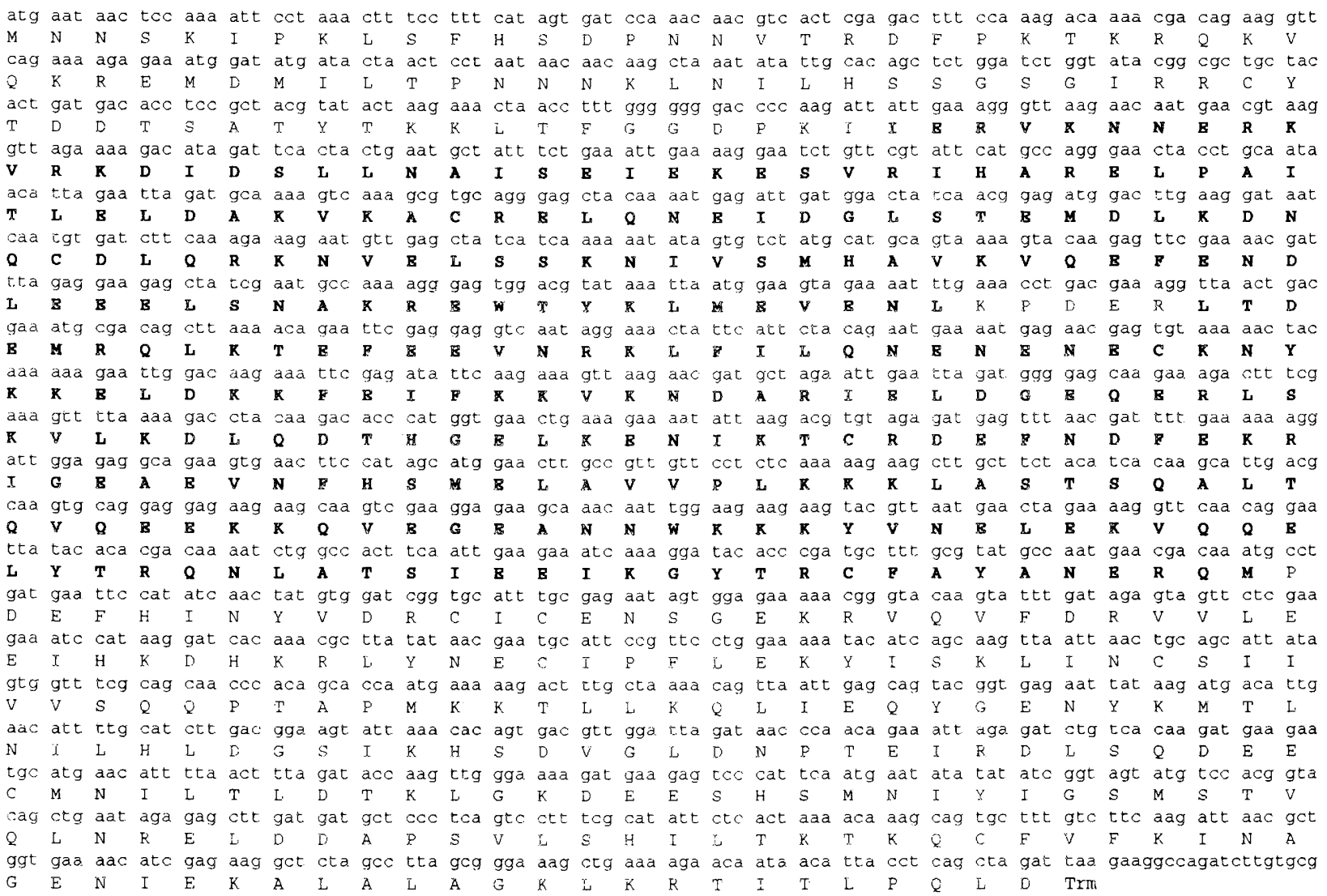
571

ctacaatcacttcgtctcgt tcccttacataaaaact tacgtagctacattgtcgtgcgtggcat caacctaattatcctagcaaaataaaagagaat gt tacgggactaacaggcgg 2043 acttcactgataggaaatcgaatagcgcacactctcttctgggacataccccaatgcggtaaagccacgaaaacaccgcgccgtaaaggggtaaacaagtccattcctacaacctcttg
2162 gagaaattcttacctactacaaccccggcgcctgatactttcagtattcatgacaactcgagccagatcccgctcgtgggcgtgtt cattctgtgacgatccactagcgacttctt 2281 ttcagcctgcaagaga

Figure 3. Nucleotide sequence of the CIK1 gene. The predicted CIK1 translation product is depicted below the nucleotide sequence. The one match and one near match to the pheromone-inducible element are underlined. Numbers adjacent to the DNA sequence refer to the nucleotide position. Italicized numbers refer to the amino acid position. The two protein regions expected to form a coiled-coil are indicated in bold; they are separated by a short break. Several phase shifts (one, three, or four acids are necessary to maintain the periodicity of the heptads (Mirzayan et al. 1992). Detailed alignment of the heptads is avaliable on request. 
81-388) of the predicted CIKl sequence exhibits weak sequence similarity to proteins that form coiled-coil structures (Cohen and Parry 1990). This region of CIKl exhibits $19 \%$ sequence identity to a region in the coiledcoil domain of rabbit cardiac myosin heavy chain (data not shown). Characteristic of coiled-coil proteins (Cohen and Parry 1990), secondary structure analysis (Garnier et al. 1978) predicts that this CIK1 central domain forms an $\alpha$-helix. Inspection of this region reveals heptad periodicity in which the first and fourth residues are hydrophobic $174 \%$ and $73 \%$ of these residues are hydrophobic, respectively); only $18 \%$ of the amino acids in the remaining positions of the heptad are hydrophobic. Thus, both sequence comparisons and secondary structure analysis predict that the CIKl protein is a coiledcoil protein.

The 5'-noncoding region of CIK1 contains sequences associated with mating pheromone induction. Within $150 \mathrm{bp}$ upstream of the open reading frame, the CIK1 sequence contains one close $(7 / 8)$ match and one exact match to the pheromone response element A/TTGAAACA (Kronstad et al. 1987; Van Arsdell and Thorner 1987) (underlined residues in Fig. 3). Multiple copies of this element exist upstream of genes whose expression is induced by $\alpha$-factor, such as FUS1 (Trueheart et al. 1987), FUS3 (Elion et al. 1990), and KAR3 (Meluh and Rose 1990). This element is bound by the STE12 protein, a transcription factor important for induction of the mating response (Dolan et al. 1989). Thus, the CIK1 gene is predicted to be regulated transcriptionally by $\alpha$-factor induction, a hypothesis consistent with data presented below.

\section{cik1:: $\beta$-gal fusion proteins localize to the SPB region}

The subcellular location of the CIK1 gene product was determined by indirect immunofluorescence by using two approaches: (1) localization of cik1:: $\beta$-galactosidase ( $\beta$-gal) fusions with anti- $\beta$-galactosidase antibodies, and (2) localization of the yeast CIK1 protein with anti-CIK 1 antibodies.

A library of cik1::lacZ disruptions (see Materials and methods) was prepared and transformed into a cik1-2 yeast strain containing the $C I K 1$ gene on a centromeric plasmid. Two in-frame fusions between CIK1 and lacZ were identified and examined by immunofluorescence with anti- $\beta$-galactosidase antibodies. The cik1-7::1acZ fusion integrated at the CIK1 chromosomal locus; and in the absence of the CIK1 plasmid, this strain exhibited phenotypes similar to those of $c i k 1^{-}$cells. The other fusion, cik1-6::IacZ, integrated at the plasmid locus and abolished the ability of the plasmid to complement the cik1-2 allele. Both cik1::lacZ alleles are recessive. Restriction mapping analysis revealed that the genomic fusion and plasmid fusion contain 1.0 and $1.5 \mathrm{~kb}$ of CIK1coding sequence upstream of $l a c Z$ (Fig. 4), respectively. Thus, these fusions contain $55 \%$ or $86 \%$ of the CIK1coding region.

Immunofluorescence with anti- $\beta$-galactosidase antibodies using standard protocols for yeast yielded mar-

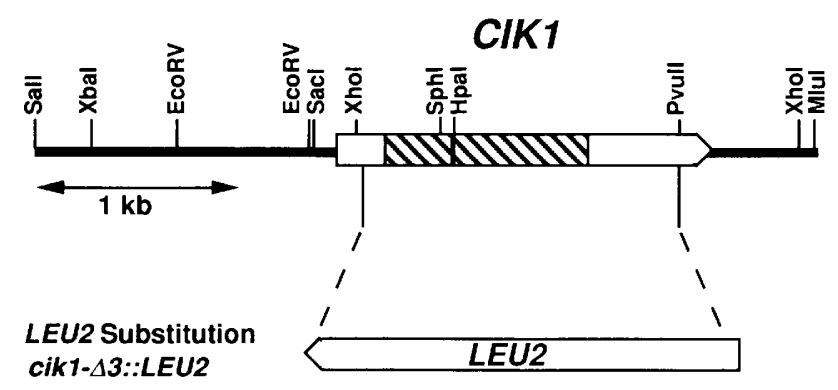

mini-Tn3 (lacZ LEU2) insertions

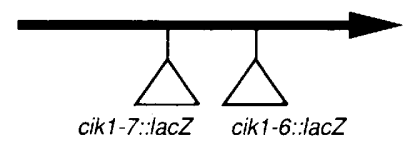

Figure 4. Restriction map of $C I K 1$, diagram of the cik1$\Delta 3:: L E U 2$ deletion allele, and location of the mini-Tn3 insertions in the CIK1 gene (for details, see Materials and methods). The CIKl region (hatched area) encodes the predicted coiledcoil domain.

ginal staining in the vicinity of the SPB for strains containing either fusion. To enhance detection of the cik $1:: \beta$-gal fusion protein, the immunofluorescent signal was amplified using a biotin-streptavidin system (see Materials and methods|. When these two cik1::lacZ strains were probed with anti- $\beta$-galactosidase antibodies and the signal was amplified, cells from each strain exhibited a brightly staining dot on the edge of the nucleus; this dot corresponded to the SPB region, as determined by double immunofluorescence with anti-tubulin antibodies (Fig. 5). Cells in all stages of the cell cycle stained at the SPB region. Unbudded cells displayed staining as a single dot, whereas large budded cells that had not yet formed a spindle contained two adjacent dots. In cells that had a spindle apparatus, a dot was present at each end of the spindle. Interestingly, in cells that contained adjacent cik1:: $\beta$-gal dots, the tubulin staining appeared as a single broader region of staining (Fig. 5 inset); two tubulin foci could not be distinguished. On the basis of this observation and the relative staining between the anti- $\beta$-gal antibodies and the anti-tubulin antibodies, we conclude that the cik $1: \because \beta$-gal protein is much more concentrated in the vicinity of the SPB and is not colocalized with tubulin. In a small subset of vegetative cells $(\sim 5 \%)$, however, weak discontinuous staining could be detected along the microtubules. In mitotic cells this staining was along the spindle apparatus (see the mitotic cell in Fig. 5 ), and in nonmitotic cells one cytoplasmic bundle was sometimes stained.

Control experiments were also performed. When cells lacking the fusion were stained with primary antibodies (anti- $\beta$-gal and anti-tubulin), no signals above background were evident for the anti- $\beta$-gal staining. Thus, the cik1::lacZ fusion is necessary for the SPB staining to be detected with the anti- $\beta$-gal antibodies. Moreover, 

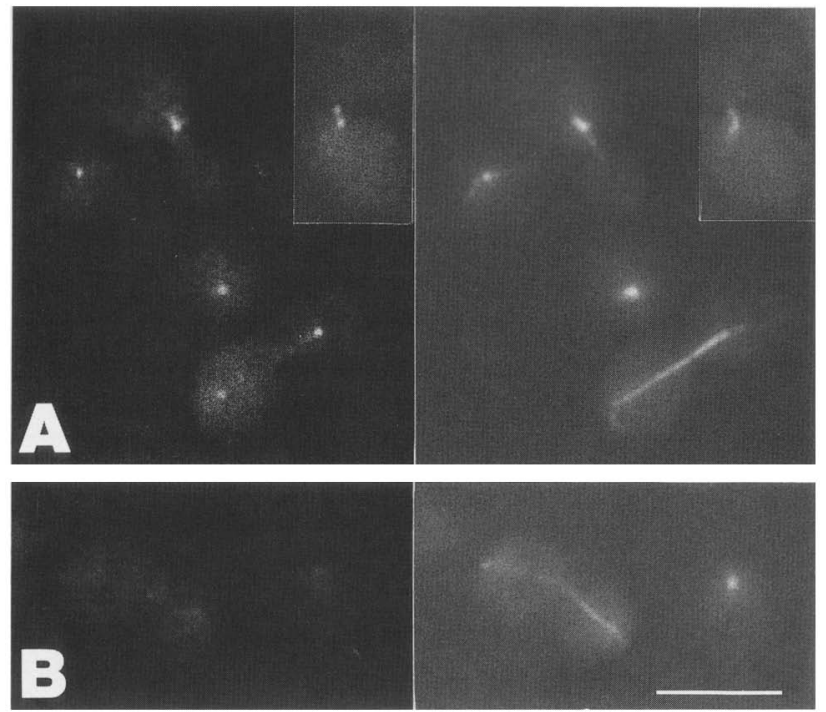

Figure 5. Localization of the cik $1:: \beta$-gal fusion protein to the SPB region by indirect immunoflourescence. The cik1-7::lacZ strain Y1099 $(A)$ and the wild-type strain Y1008 $(B)$ were stained with rabbit anti- $\beta$-gal antibodies (left) and rat anti-tubulin antibodies, YOL1/34 (right). The inset in $A$ of a cik1-7::lacZ cell illustrates the detection of adjacent SPBs with the anti- $\beta$-gal antibody. Anti- $\beta$-gal antibodies were detected by the biotinstreptavidin system (streptavidin linked to Texas Red); antitubulin antibodies were detected by anti-rat antibodies linked to FITC. Bar, $6.5 \mu \mathrm{m}$.

this experiment also indicates that the staining was not the result of a crossover signal from the tubulin staining. Consistent with this latter interpretation, a brightly staining dot at the edge of the nucleus was detected in cik1::1ac $Z$ cells stained with anti- $\beta$-gal antibodies in the absence of anti-tubulin antibodies. Thus, we conclude that cik1:: $\beta$-gal fusion proteins localize to the SPB region in vegetative cells.

Both the ability to detect SPB staining and the intensity of staining depended on whether a wild-type CIK1 gene was present in the cik1-7::lacZ cells. In the strain that contained a chromosomal cik1-7::1acZ fusion, $\sim 30 \%$ of the cells yielded a SPB signal when the CIK1 plasmid was present. In contrast, $70 \%$ of cells exhibited a clear signal at the SPB in a strain that lacked the plasmid, and this signal was stronger. In strains that exhibit heterogenous cik1:: $\beta$-gal staining, there is no obvious correlation between the cells that fail to stain and their position in the cell cycle. We interpret these results to mean that the presence of wild-type CIKl protein competes for localization of the hybrid protein.

\section{The authentic CIK1 protein localizes to the SPB}

To localize the authentic CIK1 protein in wild-type strains, polyclonal antibodies were prepared to CIK1::glutathionine $S$-transferase fusion proteins /see Materials and methods). Affinity-purified anti-CIK1 an- tibodies failed to detect the CIK1 protein in vegetative cells, even when a $2 \mu-C I K 1$ plasmid was present or when the streptavidin-biotin amplification procedures were used. Localization was observed, however, in pheromone-treated cells. When MATa cells were treated with $\alpha$-factor, $>99 \%$ of the cells arrested in late $G_{1}$ as pearshaped cells (termed shmoos); staining of these cells with anti-CIKl antibodies yielded a signal in the SPB region in every cell $(n>1000$; Fig. 6$)$. In some cells the microtubule bundle that extended to the shmoo tip exhibited a marginal level of staining (not shown). The CIK1 signal was not seen when similar $\alpha$-factor-treated cells were stained with preimmune serum. Moreover,

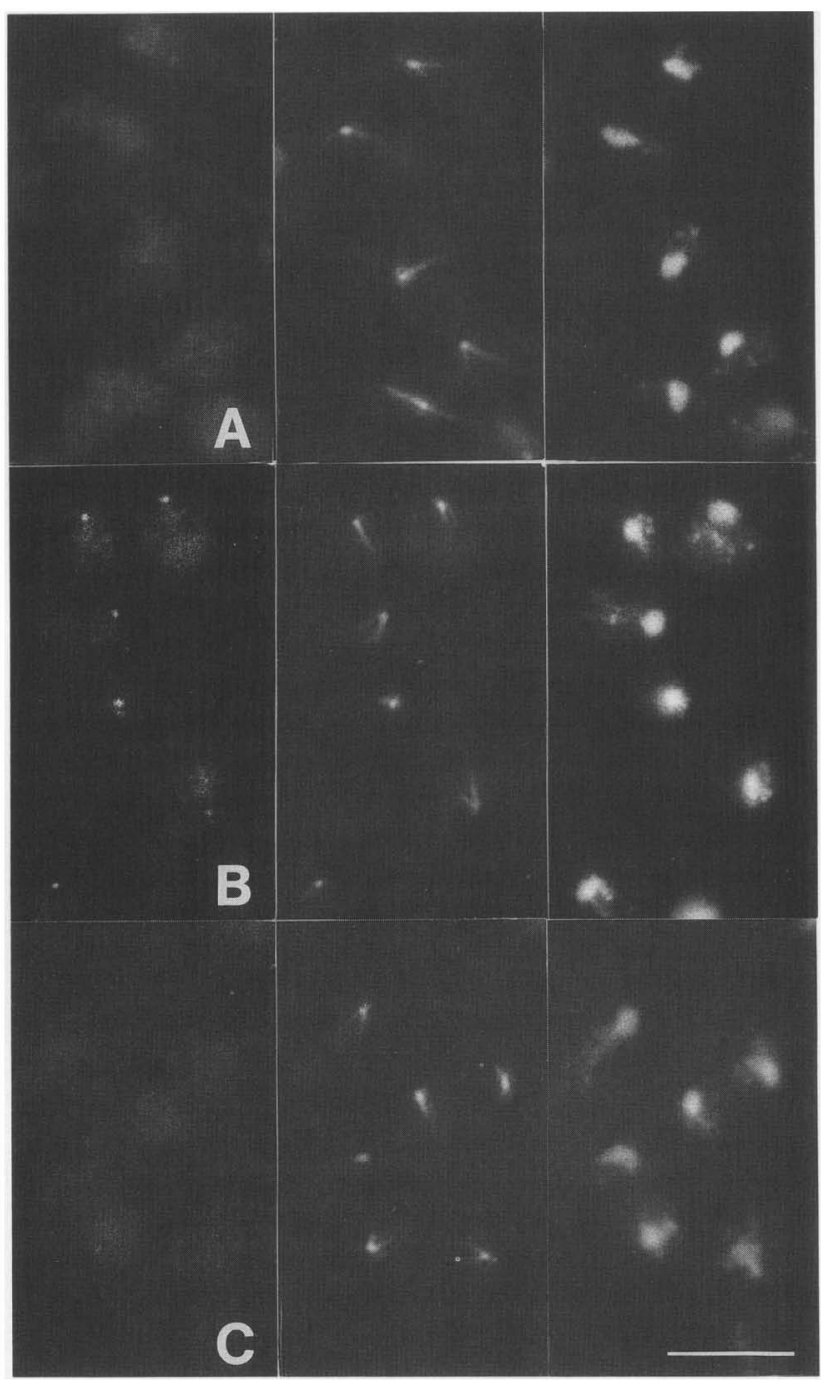

Figure 6. Localization of the authentic CIKl protein to the SPB region of $\alpha$-factor-treated cells. (Left) The indirect immunoflourescent signal of cik1- $\Delta 3$ cells (Y1119-3.7B) $(A)$ and $C I K 1^{+}$ cells $(Y 431)(B, C)$ arrested with $\alpha$-factor (Gehrung and Snyder $1990)$ and stained with either affinity-purified anti-CIK1 antibodies $(A, B)$ or preimmune serum $(C)$. (Center) The corresponding microtubule pattern detected by anti-tubulin (YOL1/34). (Right) The DNA pattern detected by Hoescht 33258. Bar, $5 \mu \mathrm{m}$. 
when cells that contained a deletion of the CIK1 gene (cik1- 43 cells; see below) were treated with $\alpha$-factor and stained with anti-CIKl antibodies, no SPB signal was observed (Fig. 6). Thus, the SPB signal is dependent on the presence of the CIK1 gene and is not the result of cross-reaction of the anti-CIK1 antibodies with other proteins.

Immunoblots of total cellular protein from various strains were probed with affinity-purified anti-CIK1 antibodies. An expected band of $\sim 77 \mathrm{kD}$ is weakly detected in both haploid and diploid wild-type strains and is clearly present in a strain with CIK1 on a $2 \mu$ plasmid (Fig. 7A). This band is absent in a cik1- $\Delta 3$ strain. Treatment of a MATa strain with $\alpha$-factor results in a dramatic increase in the level of CIK1 protein (Fig. 7). $\beta$-Galactosidase assays with the cik1-6::1acZ fusion (see Fig. 4 ) indicate that the level of activity is increased $\sim 22$-fold after treatment with $\alpha$-factor. The CIKl protein migrates slightly faster in $\alpha$-factor-treated cells than in untreated haploid cells or diploid cells. This difference in mobility is quite reproducible and has been observed in each of three experiments; the mobility difference may be the result of post-translational modifications of the CIK1 protein.

In addition to the $77-\mathrm{kD}$ CIK1 protein, lower-molecular-mass bands are detected at reduced intensity. Three of the faint bands are also visible on preimmune blots and in cik $1-\Delta 3$ strains and are apparently the result of the detection system used. The other weak band of $\sim 50 \mathrm{kD}$ appears to be a degradation product; this protein, as with the $77-\mathrm{kD}$ protein, is absent in a MATa cik1- $\Delta 3$ strain and a MATa cik1- $\Delta 3$ strain treated with $\alpha$-factor. In summary, the immunoblot analysis indicates that the $77-\mathrm{kD}$ protein is encoded by the CIK1 gene.

The increase in the level of the CIKl protein after treatment with $\alpha$-factor might be the consequence of either specific induction by $\alpha$-factor or the accumulation of the CIK 1 protein when cells arrest at late $G_{1}$ in the cell cycle. In late $G_{1}$, SPB duplication initiates with for- mation of a satellite on the cytoplasmic side of the SPB. Temperature-sensitive $c d c 28-1$ strains arrest at their restrictive temperature in late $G_{1}$ after the SPB satellite has formed; this arrest morphology is cytologically indistinguishable from that of $\alpha$-factor-treated cells (Byers and Goetsch 1973). To determine whether the enhanced level of the CIK1 protein in $\alpha$-factor-treated cells is the result of $\alpha$-factor induction or arrest at late $G_{1}$, the level of CIK1 protein in $c d c 28-1$ cells arrested at the restrictive temperature was compared with that in the $c d c 28$ 1 -arrested cells treated with $\alpha$-factor. Immunoblot analysis indicates that the CIKl protein is present at a low level in cdc28-1 cells arrested at the restrictive temperature; however, the level of the CIK1 protein becomes dramatically induced after arrested cells are treated with $\alpha$-factor (Fig. 7B). This level of induction is similar to that of $c d c 28-1$ cells grown and treated with $\alpha$-factor at the permissive temperature. Thus, the level of the CIK1 protein is induced by activation of the mating response and is not the result of preferential accumulation during late $G_{1}$. This interpretation is consistent with the existence of STE12-binding sites upstream of the CIK1 open reading frame and the importance of CIK1 for karyogamy, as described below.

The CIKl gene is essential for growth at $37^{\circ} \mathrm{C}$ and is important for microtubule-associated processes at the permissive temperature

To learn more about the role of the CIKl protein in vivo, a cik1 deletion allele (cik1- $\Delta 3)$ was constructed, in which a 1.5-kb internal fragment of CIK1 was substituted with a DNA fragment containing the LEU2 gene (Fig. 4; see Materials and methods). Deletion of the CIK1 gene revealed that $\mathrm{CIK} 1$ is not essential for viability at $25^{\circ} \mathrm{C}$ or $30^{\circ} \mathrm{C}$. cik1- $\Delta 3$ cells fail to form colonies at $37^{\circ} \mathrm{C}$, however, and exhibit a variety of other defects at permissive temperatures. The resulting phenotypes of the $c i k 1-\Delta 3$
Figure 7. (A) Identification by immunoblot analysis of a $77-\mathrm{kD}$ protein corresponding to CIK1. Total protein was isolated from yeast strains CIK1/CIK1 (Y1131), CIK1/CIK1 containing the $C I K 1$ gene on a $2 \mu$ plasmid, $C I K 1$ (Y431), and cik1- $\Delta 3$ (Y1119-3.7) grown to mid$\log$ phase. Protein was also isolated from parallel $C I K 1$ and $c i k 1-\Delta 3$ strains grown to mid-log phase and treated with $\alpha$-factor. After separation in a $10 \%$ polyacrylamide gel, the proteins were blotted to Immobilon-P and probed with affinity-purified anti-CIKl antibodies. The fainter lower-molecular-mass bands detected in the cik1- $\Delta 3$ lanes are also detected in blots probed with preimmune antibodies (not shown). For cik1- $\Delta 3$ samples, no band is detected in the $77-\mathrm{kD}$ region even after long exposures. $(B)$ The level of CIK1 protein is induced by $\alpha$-factor treatment. Total protein was isolated from MATa $c d c 28-1$ (Y168) cells that were grown at the permissive temperature $\left(25^{\circ} \mathrm{C}\right)+1-$ treatment with $\alpha$-factor $(1$ eft $)$, or shifted to the restrictive temperature $\left(37^{\circ} \mathrm{C}\right)$ for $2 \mathrm{hr}$, and then $+1-$ treatment with $\alpha$-factor after arrest (right). Detection of the primary antibody was achieved by using the Genius system (Boehringer Mannheim).

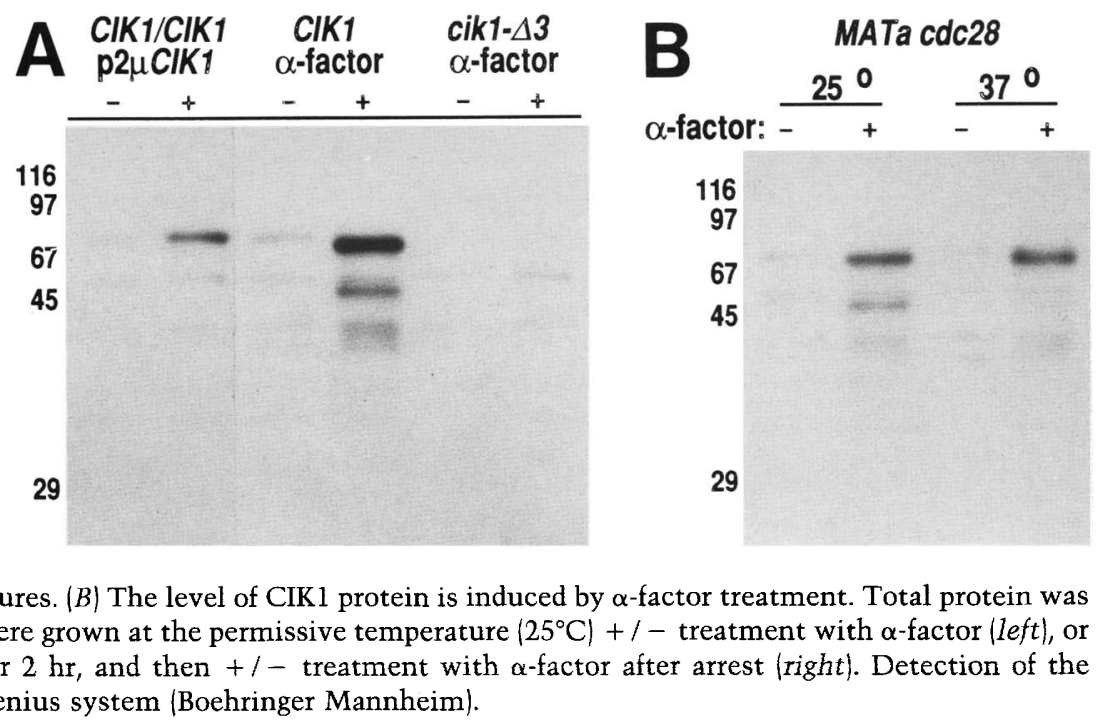


allele are similar, but not identical, to those of cik1-1 and cik1-2.

cik $1-\Delta 3$ cells exhibit defects in microtubule-associated processes, including chromosome maintenance and karyogamy. Chromosome instability was quantitated in cik1-1, cik1-2, and cik1- $\Delta 3$ strains by determining the loss rate of the dispensable chromosome derivative (Table 1). At $25^{\circ} \mathrm{C}$ wild-type strains lose the chromosome III derivative at a rate of $3 \times 10^{-4} /$ cell division. cik $1 \mathrm{mu}$ tants, however, lose the chromosome derivative at $39 \times 10^{-4}$ to $69 \times 10^{-4} /$ cell division (i.e., 13- to 23 -fold more often than wild-type cells). For cik1-2 and cik1- $\Delta 3$ strains, the chromosome loss rate was even higher at $30^{\circ} \mathrm{C}$, as determined by their sectoring phenotypes. For the cik1-2 strain, the chromosome loss rate was quantitated at this temperature and found to be 73-fold greater than that of wild-type strains.

CIK1 is also essential for karyogamy. In matings between a cik1 strain and a $C I K 1$ strain (i.e., unilateral matings), the cytoductant to diploid ratio is increased relative to matings between wild-type strains. This increase, however, depends on the particular cik1 allele used. The karyogamy defect is increased only fivefold for cik1- $\Delta 3$, whereas, this ratio is increased 150 -fold for cik1-2 (Table 2). The karyogamy defect was also examined for matings between two $c i k 1-\Delta 3$ strains (i.e., bilateral matings). Very few diploids are formed, and the cytoductant/diploid ratio is $1546\left(10^{6}\right.$-fold greater than that observed for matings between wild-type cells). For bilateral matings with cik1-1 and cik1-2 (i.e., matings between a MATa cik1-1 strain and a MAT $\alpha$ cik1-1 strain and between a MATa cik1-2 and MAT $\alpha$ cik1-2 strain), more diploids form than for the bilateral matings of cik1$\Delta 3$ strains (data not shown). Thus, the bilateral karyogamy defect of cik1-1 and cik1-2 cells is not as severe as that of cik1- $\Delta 3$ cells, whereas the reverse is true for the unilateral karyogamy defect. These results are reproducible, and an explanation for this apparent inconsistency is presented in the Discussion. In summary, at least one mating partner must have CIK1 for efficient karyogamy.

To further analyze the bilateral mating defect of cik1$\Delta 3$ strains, nuclear fusion was examined by fluorescence

Table 1. Quantitation of the chromosome derivative loss in various cik1 ${ }^{-}$strains

\begin{tabular}{llr}
\hline & \multicolumn{2}{c}{$\begin{array}{c}\text { Loss of CF/division } \\
\text { (fold increase) }\end{array}$} \\
\cline { 2 - 3 } Strain & $25^{\circ} \mathrm{C}$ & $30^{\circ} \mathrm{C}$ \\
\hline CIK1 $(\mathrm{Y} 1008)$ & $1\left\{3 \times 10^{-4}\right)$ & 1 \\
$\operatorname{cik} 1-1(\mathrm{Y} 1060)$ & 13 & 17 \\
$\operatorname{cik} 1-2(\mathrm{Y} 1128)$ & 23 & 73 \\
$\operatorname{cik} 1-\Delta 3(\mathrm{Y} 1119-3.6 \mathrm{~B})$ & 17 & N.D. \\
\hline
\end{tabular}

This quantitation is determined by the half-sectored colony assay (details in Materials and methods); at least 17,000 cell divisions were evaluated for the wild-type strain, and $>4000$ divisions were evaluated for each $c i k 1^{-}$strain.

(ND) Not determined. microscopy. Yeast strains of opposite mating types were incubated together for 5-6 hr, and the nuclei in newly formed zygotes were examined by staining with Hoechst 33258. Consistent with published observations (Byers and Goetsch 1975), in mating mixtures of wild-type strains, every zygote $(n=50)$ that had a small bud contained a single nucleus. In contrast, in mating mixtures of cik1- $\Delta 3$ cells, zygotes with a small bud contained two nuclei in every case $(n=200)$, indicative of a failure in nuclear fusion. Thus, both cytological and genetic analyses demonstrate that CIK1 is essential for karyogamy in yeast.

cikl mutants exhibit a defect in establishment and/or maintenance of a spindle apparatus

Cell-cycle defects were examined in cik1-1, cik1-2, and cik $1-\Delta 3$ diploid cells. For all three cik1- alleles, 50-60\% of cells at $25^{\circ} \mathrm{C}$ are in the large budded stage, as compared with $22 \%$ for the wild-type control. In $>70 \%$ of the large budded cik1 cells, the nucleus is positioned at the mother-bud junction and lacks a detectable spindle, as judged by tubulin staining. The remaining $30 \%$ of large budded cells have either a short or an elongated spindle. In contrast, in $90 \%$ of the large budded wild-type cells with the nucleus located at the neck, a spindle is visible. Thus, the cik1 defect appears to cause a partial block early in nuclear division.

The role of CIK1 in nuclear division is supported further by analysis of mutant cells incubated at the restrictive temperature. For all three mutants after shifting to $37^{\circ} \mathrm{C}$, the cells arrest in the first cell cycle; for cik1-1 and cik1-2, the proportion of large budded cells increases to $80 \%$. For cik $1-\Delta 3$, however, the proportion of large budded cells at the restrictive temperature remains the same as that of cells grown at the permissive temperature, and many unbudded cells are present in both populations. For each of the cik1 mutants at the restrictive temperature, the nucleus, in large budded cells, has migrated to the neck; however, no long spindles are observed. An enhanced tubulin staining in the SPB region is evident (see below and Fig. 8), which makes it difficult to ascertain whether these cells contain one or two SPBs. Staining with a less sensitive anti-tubulin antibody revealed that $\geqslant 30 \%$ of the large budded cells clearly contain two adjacent foci of staining, indicating that the SPBs had duplicated. It is possible that all of the large budded cells contain duplicated SPBs, but unfavorable focal planes made it difficult to score most cells with certainty. Thus, cik1 cells appear defective in early nuclear division at the stage of spindle formation or maintenance.

To determine whether DNA replication is also blocked in cells shifted to the restrictive temperature, the DNA content of cik1-2/cik1-2 cells grown at $25^{\circ} \mathrm{C}$ was compared with that of cells shifted to $37^{\circ} \mathrm{C}$. The endogenous DNA content of cik1-2/cik1-2 cells was determined by flow cytometric analysis of cells stained with propidium iodide, a nucleic acid-binding dye. The proportion of cells with a DNA content of $4 \mathrm{n}$ or greater increases from $\sim 60 \%$ to $\sim 90 \%$ when cik1-2 cells are 
Table 2. Quantitation of unilateral and bilateral karyogamy phenotypes for cik1 ${ }^{-}$strains

\begin{tabular}{|c|c|c|}
\hline \multicolumn{2}{|c|}{ Matings } & \multirow[b]{2}{*}{ Cytoductant/diploid at $25^{\circ} \mathrm{C}$} \\
\hline MATa & $M A T \alpha$ & \\
\hline CIK1 (Y506) & CIK1 $(\mathrm{Y} 1008 *)$ & 0.001 \\
\hline CIK1 (Y506) & $\operatorname{cik} 1-1(\mathrm{Y} 1061 *)$ & 0.028 \\
\hline CIK1 (Y506) & $\operatorname{cik} 1-2(\mathrm{Y} 1069)$ & 0.15 \\
\hline CIK1 (Y1125) & $\operatorname{cik} 1-\Delta 3(\mathrm{Y} 1119-3.8 \mathrm{C})$ & 0.005 \\
\hline $\operatorname{cik} 1-\Delta 3(\mathrm{Y} 1124)$ & $\operatorname{cik} 1-\Delta 3(\mathrm{Y} 1119-3.8 \mathrm{C})$ & 1542 \\
\hline $\operatorname{cik1-1}(\mathrm{Y} 1040)$ & $\operatorname{cik} 1-1(\mathrm{Y} 1061-1)$ & 2 \\
\hline cik1-2 (Y1062-1) & $\operatorname{cik} 1-2(\mathrm{Y} 1066)$ & 22 \\
\hline CIK1 (Y1125) & CIK1 (Y1119-3.6A) & 0.001 \\
\hline
\end{tabular}

Although only unilateral mating data for cik1-1, cik1-2, and cik1- $\Delta 3$ strains in a MAT $\alpha$ background are presented here, results are identical when MATa cik $1^{-}$cells are mated to MAT $\alpha$ wild-type cells. The mating efficiency for all unilateral matings varied from $40 \%$ to $60 \%$; for the bilateral cikI- $\Delta 3$ mating, the percentage of diploids decreased by $10^{4}$-fold.

shifted to the restrictive temperature (data not shown), indicating that DNA replication still occurs. [Wild-type diploid strains displayed the normal proportion of cells with $2 \mathrm{n}$ and $4 \mathrm{n}$ DNA contents at $25^{\circ} \mathrm{C}$ and $37^{\circ} \mathrm{C}$ /Gerring et al. 1990)l. Thus, at the restrictive temperature cik1-2 cells replicate their DNA, but they fail to establish or maintain a spindle apparatus.

\section{cikl mutants have prominent microtubule arrays}

One of the most pronounced features of cik 1 cells is their prominent microtubule arrays in both vegetative cells and $\alpha$-factor-treated cells (Figs. 8 and 9). Although this phenotype is evident in cells at different stages in the cell cycle, it is most easily quantitated in $\alpha$-factortreated cells that arrest at a uniform position in the cell cycle (Fig. 9). The number and size distribution of distinct microtubule bundles was determined in both cik1. $\Delta 3$ mutant cells and wild-type cells treated with $\alpha$-factor. The size distribution was determined relative to the size of the nucleus (which, in $\alpha$-factor-treated cells, is comparable in cik1 and wild-type cells). With our staining procedures, wild-type cells contain, on average, $\sim 1.1 \mathrm{mi}$ crotubule bundles less than or equal to the diameter of the nucleus in length (defined as a short bundle), and 1.0 bundles that are greater in length than the diameter of the nucleus (defined as a long bundle; 211 cells counted). In contrast, cik1- $\Delta 3$ mutant cells contain an average of 2.2 long bundles per cell, and about one-half of the cells contain a short bundle as well (215 cells counted). One caveat with this analysis is that very short microtubule bundles near the SPB are not distinguished as discrete entities and will not be scored. Nevertheless, of bundles that are easily scored, there are, on average, slightly more microtubule bundles visible in cik1- $\Delta 3$ cells than in wild-type cells, and these bundles are longer.

\section{Discussion}

In this report we describe a genetic screen to identify mutants important for chromosome transmission and karyogamy. Three complementation groups, CIK1,
$C I K 2$, and $C I K 3$, were identified. The CIK1 gene encodes a protein that localizes to the SPB, and genetic analysis of cik1 strains indicates that the CIK1 protein is important for a variety of microtubule-associated processes, including chromosome transmission, microtubule organization, spindle formation and/or maintenance, and karyogamy.

\section{CIK1 is associated with the SPB}

The authentic CIK1 protein can be localized to the SPB region of shmoos, and additional evidence indicates that this protein is associated with the SPB during vegetative growth. Two cik1:: $\beta$-gal fusions localize to the SPB in vegetative cells at all stages of the cell cycle. Localization of cik1:: $\beta$-gal fusions at the SPB could be partially competed by the presence of one copy of the wild-type CIK1 gene, suggesting that the authentic CIK1 protein is normally present in this location. Consistent with a role in SPB-microtubule function during vegetative growth, deletion of the CIK1 gene results in defects in cell growth and chromosome maintenance in vegetative cells.

In a small fraction of vegetative cells, weak cik $1:: \beta$-gal staining is sometimes observed along the spindle apparatus or a cytoplasmic bundle, or both. This result suggests that the CIK1 protein interacts directly or indirectly with microtubules.

The inability to localize the authentic protein in vegetative cells may be the result of a low amount of the CIK1 antigen or its inaccessibility to antibodies. Consistent with the hypothesis that the CIK1 protein is in low abundance, the protein is only detected with our most sensitive immunofluorescence and immunoblotting methods (see Results and Materials and methods), although the antibodies appear high titer by immunoblot analysis. Preparation of a second high-titer anti-CIK1 serum did not allow localization in vegetative cells /see Materials and methods), nor did examination of cells containing CIK1 on a high-copy $2 \mu$ plasmid. Immunoblot analysis revealed that cells containing the $2 \mu$ CIK1 plasmid had a greater amount of CIK1 protein than cells 

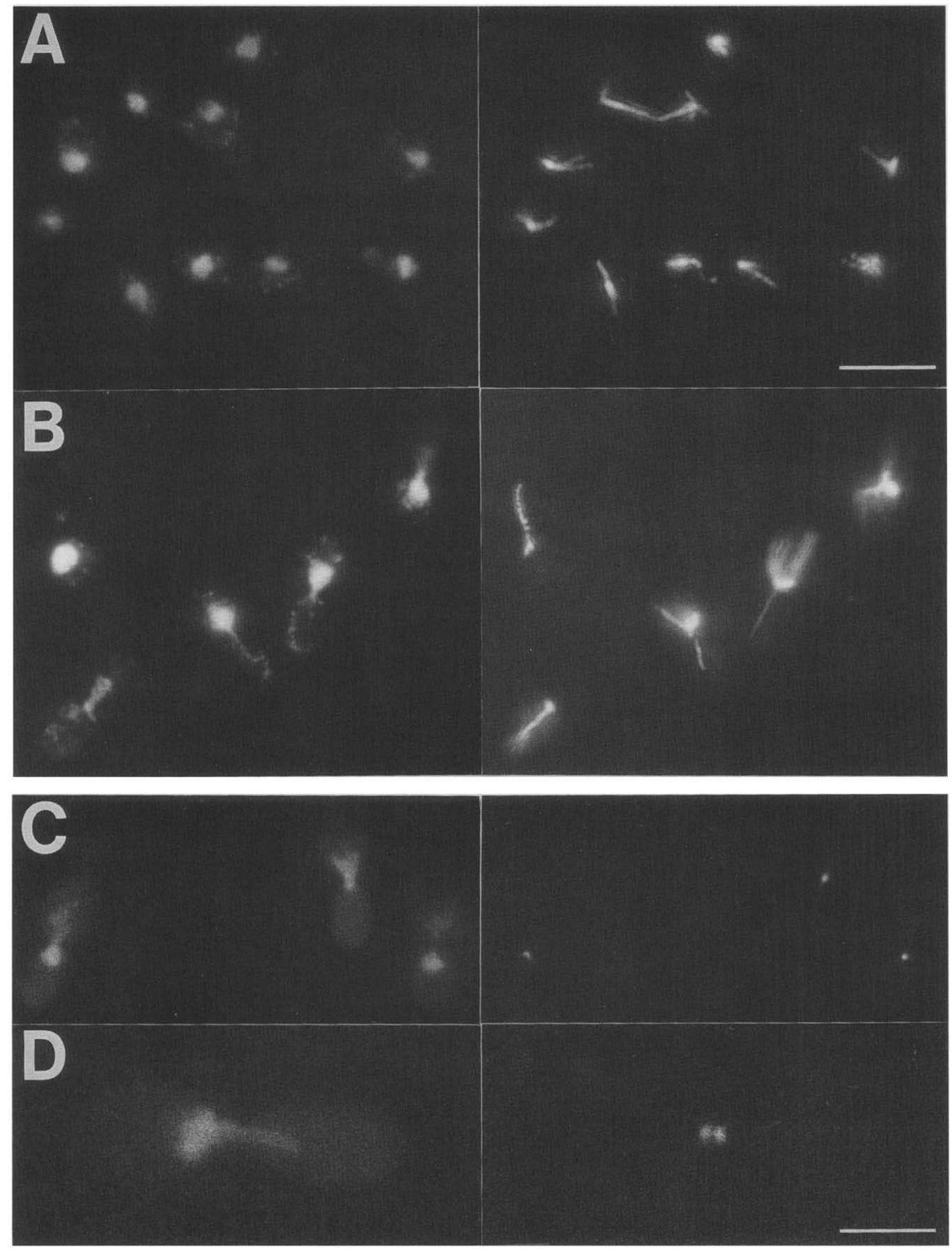

Figure 8. Immunofluorescent staining of wild-type and $c i k 1^{-}$yeast cells. DNA staining, visualized by Hoechst 33258 , of strains $C I K 1 / C I K 1$ (Y1131*) (A), cik1- $\Delta 3$ / cik1- $\Delta 3$ (Y1134) $(B)$, and cik1-1/cik1-1 $\left(\mathrm{Y} 1060^{*} / \mathrm{Y} 1061^{*}\right)(C, D)$ is displayed in the left panels. The corresponding microtubule morphology, detected by either rabbit anti-tubulin antibodies $(A, B)$ or rat antitubulin (YOL 1/34) antibodies $(C, D)$, is shown in the right panels. All strains were grown at $25^{\circ} \mathrm{C}$ to mid-log phase, shifted to $37^{\circ} \mathrm{C}$, and incubated for $3 \mathrm{hr}$ before fixation. The rat antibody is less sensitive than the rabbit antibody, allowing better resolution of the SPB region and visualization of adjacent SPBs $(D)$. Bars, $10 \mu \mathrm{m}(A-$ $C) ; 4 \mu \mathrm{m}(D)$. without the plasmid; however, this increased amount was still much less than that detected in pheromoneinduced cells that lacked this plasmid. It is also possible that the CIK1 protein is not readily accessible to antiCIKI antibodies. cik $1:: \beta-$ Gal fusions can be detected at the SPB; perhaps, the large $\beta$-gal domain is more exposed and therefore accessible to antibodies.

The CIK1 protein is different from any other cloned SPB component identified thus far, including the $110-\mathrm{kD}$ polypeptide, the SPAl protein, the KARl protein, and $\gamma$-tubulin (this latter component has been identified in other fungi). The $110-\mathrm{kD}$ polypeptide is thought to be a structural component of one layer of the SPB (Rout and Kilmartin 1990; J. Kilmartin, pers. comm.), the KAR1 protein is thought to be associated with the satellite (Vallen et al. 1992), and $\gamma$-tubulin is an SPB component postulated to be involved in microtubule assembly (Oakley 1992; Oakley et al. 1990). The role of SPAl is not known (Snyder and Davis 1988). The CIKl protein is the only member of this group that has been shown to be differentially regulated with particular phases of the yeast life cycle.

\section{The CIK1 protein is important during vegetative} growth and essential during karyogamy

The CIK1 protein is important, but not essential, for vegetative growth. cik 1 cells lose a chromosome derivative at an elevated frequency. Other yeast mutants that lose a similar chromosome derivative also lose endogenous yeast chromosomes (Hartwell and Smith 1985; Palmer et al. 1990; Spencer et al. 1990); hence, we expect that cik1 mutants lose endogenous chromosomes as well. Consistent with this interpretation, cik1 cells also appear aneuploid by flow cytometric analysis, suggesting a high 


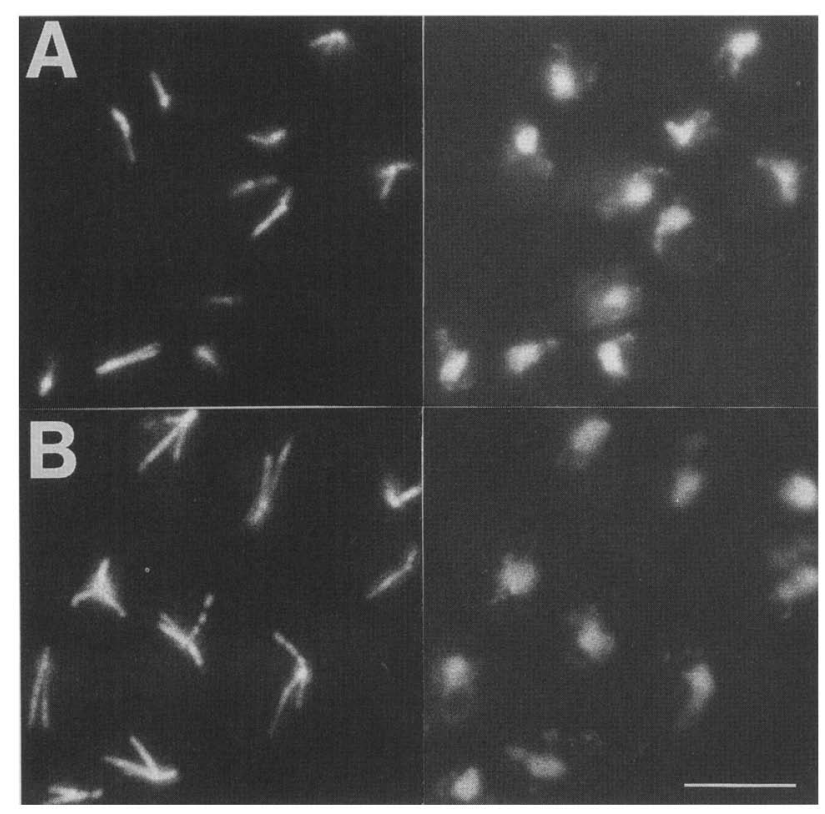

Figure 9. Immunofluorescence of wild-type and cik1- $\Delta 3$ cells treated with $\alpha$-factor. The microtubule morphology (left panels) of wild-type (Y431) and cik1- $\Delta 3$ (Y1119-3.7B) cells after treatment with $\alpha$-factor was detected with rabbit anti-tubulin antibodies. The corresponding Hoechst 33258 DNA staining is shown in the right panels. The more sensitive anti-tubulin antibody was used in this experiment, whereas the less sensitive rat anti-tubulin antibody was used in the experiment shown in Fig. 6. Quantitation of the microtubule number and length was determined as described in the text. Bar, $5 \mu \mathrm{m}$.

frequency of endogenous chromosome loss and nondisjunction (data not shown).

cik1 cells fail to grow at $37^{\circ} \mathrm{C}$. Inability to grow at this temperature is not simply the result of elevated chromosome loss. cik1 cells arrest during the first cell cycle, and the majority are blocked in early nuclear division. The arrest phenotype of most cells is consistent with failure to form and/or maintain a spindle apparatus.

Although CIK1 is not essential for vegetative growth, $C I K 1$ is required for efficient karyogamy. When cik $1-\Delta 3$ cells are mated to other cik $1-\Delta 3$ cells, very few diploids are formed, although the cells still mate and fuse their cytoplasms as evidenced by the high frequency of cytoductants. When cik1- $\Delta 3$ cells are mated to wild-type cells, however, the karyogamy defect is small. One explanation for these observations is that in unilateral matings, the CIKl protein can diffuse within the heterokaryon and complement the deleted strain. Cytoplasmic transfer has been proposed to explain the contrasting severity of the unilateral and bilateral defects of tub2401, tub2-104 (Huffaker et al. 1988), bik1-1 (Berlin et al. 1990 ), and kar3- $\Delta 100$ (Meluh and Rose 1990) strains. As with cik1- $\Delta 3$, these mutants exhibit strong bilateral mating defects but less severe unilateral mating defects.

Interestingly, cik1-1 and, particularly, cik1-2 strains have a stronger unilateral karyogamy defect than cik1-
$\Delta 3$ cells (Table 2), although the bilateral defect of cik1-1 and cik1-2 strains is weaker than that of cik1- $\Delta 3$ cells (Table 2). One explanation for this observation is that in unilateral matings, a partially active cik1-1 and cik1-2 mutant protein assembles at the SPB and interferes with karyogamy. In bilateral matings, both cells will be partially defective and karyogamy can still occur at a reduced level. In contrast, in bilateral matings between cik1- $\Delta 3$ strains, no protein is present and karyogamy does not occur. In unilateral matings between cik1- $\Delta 3$ and wild-type strains, the wild-type protein can assemble at the SPB that lacks the CIK1 protein. This hypothesis suggests that the cik 1-1 and cikl-2 mutant proteins preassemble into the SPB region before cell fusion.

The increased level of CIK1 protein at the SPB during mating provides the first evidence that molecular changes occur at the MTOC as it prepares for karyogamy. Such changes are not evident at a cytological level; electron microscopic analysis of SPB morphology after treament of cells with $\alpha$-factor has not detected an alteration distinct from that of cells arrested during late $G_{1}$ (Byers and Goetsch 1973). Previous studies have indicated that nuclear fusion requires induction of the mating response; heterokaryons formed from cells that have not been exposed to mating pheromones do not fuse their nuclei (Rose et al. 1986). Thus, cells must be in an "activated" state to fuse their nuclei. On the basis of the evidence presented above, the CIKl protein is likely to be involved in formation of this activated state.

\section{Possible functions of $\mathrm{CIKI}$ in yeast}

cik1 mutants exhibit defects in establishment and/or maintainance of a spindle apparatus, and they are also defective in karyogamy. Both of these processes involve movement of SPBs relative to one another (albeit in opposite directions). cik1 mutants still execute several important microtubule functions. SPB orientation and nuclear migration occur in vegetative cells and in shmoos, and cik1 cells contain enhanced microtubule arrays. One of the most pronounced phenotypes of cik 1 mutants is that they have more discernible microtubule bundles on average, and these bundles are longer. The increased number of microtubules visible in cik1 cells might not be the result of increased nucleation at the SPB but may result from the increase in microtubule length. In any event, CIK1 is probably not important for microtubule assembly, the most widely believed role for the MTOC.

There are several possibilities for the role of the CIK1 protein in yeast. One possibility is that the CIK1 protein is involved in microtubule disassembly at the SPB. In multicellular organisms the major site of microtubule assembly and disassembly is at the "plus" ends of microtubules, which are oriented away from the MTOC (Euteneur and McIntosh 1981; Telzer and Haimo 1981; Mitchison and Kirschner 1984; Horio and Hotani 1986). A flux of microtubule subunits toward the poles also occurs, however, suggestive of microtubule disassembly at the MTOC (Mitchison 1989). A defect in microtubule disassembly at the SPB in cik1 cells could account for 
the increased number of microtubule bundles and longer microtubules visible in these cells. Moreover, as karyogamy requires the disassembly of microtubules in the movement of SPBs toward one another, a defect in disassembly at the SPB in cik1 cells could account for the failure of nuclear fusion during mating.

A second possible CIK1 function, which is not exclusive with that proposed above, is in microtubule capture. The microtubule-dependent processes most affected by deletion of the CIK1 gene, maintenance of a spindle apparatus and karyogamy, both involve interconnection of two SPBs by microtubules. Both of these processes might involve microtubule capture at the SPB. Electron microscopic analysis of spindle microtubules suggests that at least some microtubules extend continuously from pole to pole (Peterson and Ris 1976); this interaction might occur by a microtubule capture site located at the SPB. A defect in such a microtubule capture site could result in failure to retain an extended spindle by pole-to-pole microtubules; spindle collapse presumably results in cell cycle arrest with two adjacent SPBs (Jacobs et al. 1988). Microtubule capture at the SPB might be particularly important for karyogamy. Capture of microtubules at the SPB might interconnect the two nuclei; disassembly while still maintaining attachment (analogous to a kinetochore) would draw the two nuclei together. The CIK1 protein might be a component of such a capture site at the SPB. The small amounts of CIK1 protein along microtubules might also serve to capture and/or cross-link interdigitating bundles emanating from two SPBs.

\section{The karyogamy-chromosome maintenance genetic screen}

The CIK1 gene was isolated from a screen designed to identify genes involved in microtubule and SPB function. Because the CIK1 protein localizes to the SPB and participates in a variety of microtubule-associated processes, this screen appears to be a useful strategy to identify new SPB and/or microtubule components. By using this approach, two other complementation groups, CIK2 and $C I K 3$, which may also be important for microtubuledependent processes, have been identified. Furthermore, this screen is clearly not saturated; only one or two alleles of each CIK gene have been isolated, and SPA1, $K A R 1$, or KAR3, which participate in both karyogamy and chromosome maintenance, have not been identified. Therefore, several new genes are expected to be identified by this method. Analysis of such genes should help illuminate how microtubules and/or their organizing centers function.

\section{Materials and methods}

\section{Strains, media, and microbiological techniques}

All yeast strains used in this study are congenic (S288C background); they are listed in Table 3. General molecular cloning techniques were as described in Maniatis et al. (1982), and yeast genetic manipulations and growth media were as presented in Sherman et al. (1986).

\section{Isolation of cik mutants}

Strain Y1009, which contains a 150-kb chromosome III derivative (described in Spencer et al. 1990), was mutagenized with UV light to $50 \%$ viability and allowed to recover by growth in the dark for $14 \mathrm{hr}$. Y1009 cells were incubated with Y 1010 cells at concentrations of $4 \times 10^{6} \mathrm{cells} / \mathrm{ml}$ and $1.2 \times 10^{7}$ cells $/ \mathrm{ml}$, respectively. After $13 \mathrm{hr}$ at $25^{\circ} \mathrm{C}$ the mating mixture was then diluted 10 -fold and spread on synthetic complete plates containing $3 \%$ glycerol, $0.1 \%$ glucose, $60 \mu \mathrm{g} / \mathrm{ml}$ of canavanine, and $6-9$ $\mu \mathrm{g} / \mathrm{ml}$ of adenine. Sectoring colonies that lost the SUP11 chromosome at a high frequency were identified.

From six independent screenings, 700 high-frequency sectoring colonies were obtained; these constituted only $5 \%$ of the total number of cytoductants selected. After retesting the sectoring phenotype, 92 were confirmed as exhibiting a high frequency of chromosome loss. These mutants were evaluated by the karyogamy assay (see below). Of these 92 strains, 13 gave a cytoductant to diploid ratio $\geqslant 10$-fold than that of matings between wild-type cells. Of the 13,6 were temperature sensitive for growth at $37^{\circ} \mathrm{C}$, and 4 of these were analyzed further.

\section{Karyogamy assay}

Potential karyogamy mutants were evaluated by a modification of the Dutcher and Hartwell (1982) assay. For the unilateral karyogamy assay, $20 \mu \mathrm{l}$ of a $c y h^{R} \rho^{0}$ strain at $2 \times 10^{7} \mathrm{cells} / \mathrm{ml}$ was mixed with $20 \mu \mathrm{l}$ of a $C Y H^{s} \rho^{+}$strain at $5 \times 10^{6} \mathrm{cells} / \mathrm{ml}$ and incubated on a YPD plate for $12 \mathrm{hr}$. The mating mixture was then resuspended to $1 \times 10^{7} \mathrm{cells} / \mathrm{ml}$. Approximately $2 \times 10^{6}$ cells were plated per cytoductant selection plate $(1 \mu \mathrm{g} / \mathrm{ml}$ of cycloheximide, $3 \%$ glycerol, plus $0.1 \%$ glucosel, and 100 -fold fewer cells were plated per diploid selection plate. For bilateral karyogamy analysis of cik1- $43:: L E U 2$ strains, MATa $c a n^{R} c i k 1$ $\Delta 3 \rho^{o}$, and MAT $\alpha C A N^{S}$ cik1- $\Delta 3 \rho^{+}$strains were mated to one another as described above. Tests were performed in duplicate; and for unilateral matings, 200-500 diploid colonies were scored for each test. Cytoductants were selected on plates containing $60 \mu \mathrm{g} / \mathrm{ml}$ of canavanine, $3 \%$ glycerol, and $0.1 \%$ glucose. Cytoductants were verified to be the expected haploid exconjugants by determining mating-type and auxotrophic phenotypes (His ${ }^{+}$or $\operatorname{Trp}^{+}$, depending on the particular strain tested). All karyogamy assays were carried out at $25^{\circ} \mathrm{C}$ and were repeated in four separate experiments.

\section{Quantitation of chromosome derivative loss rate}

To determine the rate at which the chromosome derivative is lost, cells were grown under selective conditions for the chromosome derivative and plated at low density 250 cells per plate) onto synthetic complete plates that allowed loss of the chromosome derivative and colony color development (Hieter et al. 1985|. After incubation at either $30^{\circ} \mathrm{C}$ or $25^{\circ} \mathrm{C}$ for 5 days, the number of half-sectored colonies was determined relative to the total number of colonies that contained the chromosome derivative. This represents the number of first divisions in which the chromosome derivative was lost and yields the rate of loss per cell division (Hieter et al. 1985).

\section{Cloning of CIK1}

The CIK1 gene was cloned by using a YCp50 genomic library (Rose et al. 1987) to complement the cik1-2 temperature-sensitive phenotype. Strain Y1062 was transformed with this library and incubated at $37^{\circ} \mathrm{C}$. Of $\sim 2700$ transformants, five colonies grew well at $37^{\circ} \mathrm{C}$ and two colonies grew poorly at this temper- 
Page and Snyder

Table 3. Yeast strains

\begin{tabular}{|c|c|}
\hline Strain & Genotype \\
\hline Y168 & MATa his7 ural cdc28-1 \\
\hline Y427 & MAT $\alpha$ ura3-52 lys2-801 ade2-101 his3-200 leu2-98 CFIII/CEN3. L. ${ }^{\mathrm{a}}$ \\
\hline Y431 & MATa ura3-52 lys2-801 ade2-101 trp1-901 leu2-98 CF111(D8B d.) $)^{\mathrm{a}}$ \\
\hline Y506 & MATa ura3 cyh2 can1 leu1 ade2 $\rho^{o}$ \\
\hline Y1008 & MATa ura3-52 lys2-801 ade2-101 his3-200 leu2-98 CFIII(CEN3. L.)can1-100 \\
\hline Y1009 & MAT $\alpha$ ura3-52 lys2-801 ade2-101 his3-200 leu2-98 CFIII|CEN3. L.|can1-100 $\rho^{o}$ \\
\hline Y1010 & MATa ura3-52 LYS2 ADE2 trp1-901 leu2-98 \\
\hline Y1021 & MAT $\alpha$ ura3-52 lys2-801 ade2-101 his3-200 leu2-98 can1-100 cik3-1CF \\
\hline Y1032 & MAT $\alpha$ ura3-52 lys2-801 ade2-101 leu2-98 his3-200 can1-100 cik1-1 CF \\
\hline Y1040 & MATa ura3-52 lys2-801 ade2-101 his3-200 leu2-98 cik1-1 \\
\hline Y1042 & MAT $\alpha$ ura 3 cyh2 can1 leu1 ade $2 \rho^{o}$ \\
\hline Y1059 & MAT $\alpha$ ura3-52 lys2-801 ade2-101 leu2-98 his3-200 can1-100 cik1-2 CF \\
\hline Y1060 & MATa ura3-52 lys2-801 ade2-101 leu2-98 his3-200 can1-100 cik1-1 CF \\
\hline Y1061 & MAT $\alpha$ ura3-52 lys2-801 ade2-101 leu2-98 trp1-901 can1-100 cik1-1 \\
\hline Y1061-1 & MAT $\alpha$ ura3-52 lys2-801 ade2-101 leu2-98 trp1-901 can1-100 cik1-1 $\rho^{o}$ \\
\hline Y1062 & MATa ura3-52 lys2-801 ade2-101 leu2-98 his3-200 can1-100 cik1-2 \\
\hline Y1062-1 & MATa ura3-52 lys2-801 ade2-101 leu2-98 his3-200 can1-100 cik1-2 $\rho^{o}$ \\
\hline Y1066 & MAT $\alpha$ ura3-52 lys2-801 ade2-101 leu2-98 trp1-901 cik1-2 \\
\hline Y1069 & MAT $\alpha$ ura3-52 lys2-801 ade2-101 leu2-98 trp1-901 can1-100 cik1-2 \\
\hline Y1072 & MAT $\alpha$ ura3-52 lys2-801 ade2-101 his3-200 leu2-98 can1-100 cik2-ICF \\
\hline Y1093 & MAT $\alpha$ ura3-52 lys2-801 ade2-101 leu2-98 CIK1::LEU2 \\
\hline Y1094 & cik1-5::lacZ plasmid integration of Y1129 \\
\hline Y1095 & cik1-7::lacZ genomic integration of $\mathrm{Y} 1129$ \\
\hline Y1098 & cik1-6::lacZ plsamid integration of Y1129 \\
\hline Y1099 & Y1095 derivative minus YCp50-CIK1 plasmid \\
\hline Y1119 & cik1- $\Delta 3::$ Leu2/CIK1 derivative of Y1131 \\
\hline Y1119-1.1C & MAT $\alpha$ ura3-52 lys2-801 ade2-101 trp1-901 cik1- $\Delta 3:: L E U 2$ \\
\hline Y1119-2.1C & MATa ura3-52 lys2-801 ade2-101 leu2-98 trp1-901 \\
\hline Y1119-2.6D & MATa ura3-52 lys2-801 ade2-101 leu2-98 trp1-901 can1-100 \\
\hline Y1119-3.6A & MATa ura3-52 lys2-801 ade2-101 leu2-98 his3-200 \\
\hline Y1119-3.6B & MAT $\alpha$ ura3-52 lys2-801 ade2-101 leu2-98 cik1-43::LEU2 CF \\
\hline Y1119-3.7B & MATa ura3-52 lys2-801 ade2-101 cik1-43::LEU2 \\
\hline Y1119-3.7D & MATa ura3-52 lys2-801 ade2-101 his3-200 cik1-A3::LEU2 can1-100 \\
\hline Y1119-3.8B & MATa ura3-52 lys2-801 ade2-101 leu2-98 trp1-901 can1-100 cik1-43::LEU2 \\
\hline Y1119-3.8C & MATo ura3-52 lys2-801 ade2-101 leu2-98 his3-200 cik1- $\Delta 3:: L E U 2$ \\
\hline Y1124 & MATa ura3-52, lys2-801 ade2-101 leu2-98 trp1-901 can1-100 cik1-43::LEU2 $\rho^{o}$ \\
\hline Y1125 & MATa ura3-52 lys2-801 ade2-101 leu2-98 trp1-901 can1-100 $\rho^{0}$ \\
\hline Y1128 & MATa ura3-52 lys2-801 ade2-101 leu2-98 cik1-2 CF \\
\hline Yl1 $128^{\mathrm{b}}$ & Y1128 without $C F$ \\
\hline Y1129 & Y1128 ${ }^{\mathrm{b}}$ carrying plasmid YCp50-CIK1 \\
\hline Y1130 & Y1062 mated to Y1093 \\
\hline Y1131 & $\mathrm{Y} 1008^{\mathrm{b}}$ mated to $\mathrm{Y} 431$ \\
\hline Y1132 & Y1119-1.1C plus plasmid YCp50-CIK1 \\
\hline Y1133 & Y1132 mated to Y1119-3.7D \\
\hline Y1134 & Y1133 minus plasmid YCp50-CIK1 \\
\hline
\end{tabular}

${ }^{a}$ (D8B d.) and (CEN3. L.) are types of chromosome fragments (Spencer et al. 1990).

benotes strain without $C F$.

ature. Restriction mapping analysis revealed that the plasmids from the strains that grew well at $37^{\circ} \mathrm{C}$ comprised one set of overlapping DNA fragments (the CIK1 plasmids), and the plasmids from the strains that grew poorly comprised a second set of overlapping inserts (the $S C K 1$ plasmids) that will be described elsewhere. Standard deletion analysis (Costigan et al. 1992) localized the smallest complementing region of the CIKl clone to a 3.6-kb SalI-MluI DNA fragment (see Fig. 4). To evaluate the complementation of the high-frequency sectoring phenotype, the Sall-MluI 3.6-kb fragment was subcloned into the pRS315 LEU2 vector (Sikorski and Hieter 1989). This construct com- plemented all three $c i k 1^{-}$mutant phenotypes (karyogamy defect, chromosome loss, and temperature-sensitive growth defect).

To determine whether the complementing DNA corresponds to the CIK1 gene, a LEU2 transposon marker (see below) was integrated at the genomic location of the cloned DNA (Rothstein 1983). This CIK1 LEU2 strain was mated to an appropriate cik1-2 strain, and the resulting diploid was sporulated. In the eight tetrads analyzed, the $\mathrm{Cik1}^{-}$temperature-sensitive phenotype and the $L E U 2^{+}$marker did not cosegregate, indicating that the cloned DNA is tightly linked to the CIK1 gene $(<6 \mathrm{cM})$. 


\section{Transposon mutagenesis of $\mathrm{CIK} 1$}

A library of $c i k 1:: 1 a c Z$ fusion-disruption alleles was generated by transposon mutagenesis in Escherichia coli (Siefert et al. 1986). The 3.6-kb CIK1 DNA fragment was subcloned into pHSS6 vector and mutagenized with a LEU2 transposon that contains at one end a lacZ gene lacking an ATG and promoter sequences. Forty random $C I K 1$ mutagenized clones were isolated, and the location and orientation of the transposon within CIK1 was determined by restriction mapping. These clones were digested with NotI and used to transform strain Y1129 that possesses the plasmid pYCp50-CIK1. The site of integration (i.e., genomic or plasmid) was determined as well as the consequence of the integration on the Cik1 phenotype.

A library of random transposon disruptions of CIK1 was digested with NotI and transformed into the above yeast strain. Four transformants that had detectable $\beta$-galactosidase activity contained fusion proteins that localized to the SPB when stained with anti- $\beta$-galactosidase antibodies. Two cik1::lac $Z$ fusions integrated at the chromosomal cik1 locus, and two integrated on the plasmid. The $c i k 1:: 1 a c Z$ plasmid integrations were rescued into $E$. coli and subjected to restriction mapping analysis. The two plasmid integrations /which were independently derived) yielded similar restriction patterns indicating that the site of the fusion between CIK1 and lacZ was $1.5 \mathrm{~kb}$ downstream of the first ATG of the CIK1 open reading frame for each case. We do not know whether the two plasmid fusions are in the exact same location. The genomic integrations of cik1::lacZ were evaluated by DNA blot analysis. For the two genomic integrations (which were also independently derived), the site of cik1-2 and lacZ fusion also appeared similar, $1.0 \mathrm{~kb}$ downstream of the presumed start. As above, we do not know whether these fusions are identical. In any event, at least two different cik1::lacZ fusions localize to the SPB, although four independent transformants gave a similar pattern. For presentation purposes, only one plasmid fusion and one chromosomal fusion are described in the text.

\section{Disruption of CIK1}

The CIK1 deletion was constructed by replacing the $1.5-\mathrm{kb}$ Xho-PvuII CIK1 fragment with a 2.2-kb SalI-HpaI fragment of LEU2 (Hill et al. 1986). The direction of LEU2 transcription is opposite that of CIK1. If translation initiates with the first AUG of the CIK1 open reading frame, this deletion encodes only the first 18 amino acids of the CIK1 protein. A $3.1-\mathrm{kb}$ SacI-XhoI DNA fragment (see Fig. 4) containing the cik1- $\Delta 3$ allele was transformed into diploid strain Y1131, and the resulting strain sporulated. Proper substitution of CIK1 with the cik1- $43:: L E U 2$ allele was confirmed by DNA blot analysis of the heterozygous diploid cik1- $\triangle 3:: L E U 2 / C I K 1$ and the haploid progeny of two tetrads.

A cik1- $\triangle 3:: L E U 2$ homozygous diploid was constructed by transforming yeast strain Y1119-1.1C with a CIK1/URA3/CEN plasmid and mating the transformant to strain Y1119-3.7D. The resulting diploids were streaked onto 5 '-fluoro-orotic acid $(5$ 'FOA) plates to select for $c i k 1-\Delta 3 / c i k 1-\Delta 3$ cells that have lost the URA3 plasmid.

\section{DNA sequence analysis}

Two sets of overlapping unidirectional deletions of the 3.6-kb SalI-MluI fragment of CIK1 were generated (Henikoff 1984) (Erase-a-Base system, Promega) and clones were sequenced by the dideoxy chain termination method (Sanger et al. 1977) with the Pharmacia T7 sequencing kit. Both DNA strands were se- quenced. The CIKl-predicted amino acid sequence was compared with the GenBank data base by use of the tFASTA program (Pearson 1990). The accession number for the CIK1 DNA sequence is M96439.

\section{Flow cytometry analysis}

Cells were fixed in $70 \%$ ethanol, treated with RNase A (Sigma), and stained with propidium iodide (Boehringer Mannheim) as described (Hutter and Eipel 1978). For each sample, the DNA content of 10,000 cells was determined.

\section{Production of antibodies to CIK1 protein}

To isolate the CIKl protein for antibody production, two different gene fusions between $C I K 1$ and the E. coli glutathione $S$-transferase gene were constructed. The 0.9-kb SnaBI-MscI CIK1 fragment and the l-kb HpaI-PvuII CIK1 fragment were each cloned into the SmaI site of pGEX-2T (Smith and Johnson 1988 ) to produce CIK1-SM::GST and CIK1-HP::GST fusion proteins, respectively. By use of published procedures (Smith and Johnson 19881, $4 \mathrm{mg}$ of the 60-kD CIKl-SM fusion protein and $10 \mathrm{mg}$ of the $67-\mathrm{kD}$ CIK1-HP::GST fusion protein were recovered per liter of culture.

Two hundred fifty micrograms of protein was used for the first injection into a rabbit; $150 \mu \mathrm{g}$ was used for boost injections every 2-3 weeks (Pocono Rabbit Farm and Laboratory). Both preimmune and immune antibodies were affinity purified as described (Snyder 1989). The anti-CIK1-SM antibodies recognized the CIK1-SM::GST fusion protein on immunoblots and appeared to be high titer; however, these antibodies gave no signal in immunofluorescence experiments with whole yeast cells. Anti-CIK1-HP antibodies successfully stained the SPB and were used in all experiments.

\section{Immunoblot analysis and immunofluorescence}

Preparation of yeast proteins and immunoblot analysis were performed according to Snyder (1989). Indirect immunofluorescence of yeast cells with anti-tubulin antibodies (Figs. 8 and 9) was performed as described (Adams and Pringle 1984). Rabbit anti-yeast $\beta$-tubulin was kindly provided by Dr. Frank Solomon (Bond et al. 1986). The rat anti-tubulin monoclonal antibody YOL1/34 (Kilmartin et al. 1982) was obtained from Sera-lab. Goat anti-rodent secondary antibodies linked to either FITC or Texas Red and anti- $\beta$-galactosidase antibodies were obtained from Cappel Laboratories. To facilitate detection of the CIK1::ß-gal or CIK1 proteins, a streptavidin-biotin amplification procedure was employed. This procedure required blocking of the endogenous yeast biotin by use of incubations with strepavidin and biotin. After incubation with the primary antibody, a secondary antibody incubation with biotin-linked antirabbit antibodies was performed and followed by a third incubation with streptavidin linked to Texas Red (Zymed). Detailed protocols are available on request. Yeast nuclei were visualized with the DNA stain Hoechst 33258.

$\alpha$-Factor-treated cells were prepared as described (Gehrung and Snyder 1990).

\section{Acknowledgments}

We thank B. Rockmill, H. Friedman, and R. Padmanabha for stimulating discussions and B. Rockmill, H. Friedman, B. Grimwade, K. Madden, and R. Padmanabha for critical comments on the manuscript. This research was supported by a grant from the National Institutes of Health (NIH) (GM36494) and used equip- 
ment purchased with the help of Pew Scholars Funds. B.D.P. was supported in part by a training grant from N.I.H.

The publication costs of this article were defrayed in part by payment of page charges. This article must therefore be hereby marked "advertisement" in accordance with 18 USC section 1734 solely to indicate this fact.

\section{References}

Adams, A.E.M. and J.R. Pringle. 1984. Relationship of actin and tubulin distribution to bud growth in wild-type and morphogenetic-mutant Saccharomyces cerevisiae. I. Cell Biol. 98: 934-945.

Barnes, G., K.A. Louie, and D. Botstein. 1992. Yeast proteins associated with microtubules in vitro and in vivo. Mol. Biol. Cell 3: 29-47.

Baum, P.C., C. Furlong, and B. Byers. 1986. Yeast gene required for spindle pole body duplication: Homology of its product with $\mathrm{Ca}^{2+}$ binding proteins. Proc. Natl. Acad. Sci. 83: 55125516.

Baum, P., C. Yip, L. Goetsch, and B. Byers. 1988. A yeast gene essential for regulation of spindle pole body duplication. Mol. Cell Biol. 8: 5386-5397.

Berlin, V., C.A. Styles, and G.R. Fink. 1990. BIK1, a protein required for microtubule function during mating and mitosis in Saccharomyces cerevisiae, colocalizes with tubulin. $J$. Cell Biol. 111: 2573-2586.

Bond, J., J. Fridovich-Keil, L. Pillus, R. Mulligan, and F. Solomon. 1986. A chicken-yeast chimeric beta-tubulin protein is incorporated into mouse microtubules in vivo. Cell 44: 461-468.

Brinkley, B.R. 1985. Microtubule organizing centers. Annu. Rev. Cell Biol. 1: 145-172.

Byers, B. 1981. Cytology of the yeast cell cycle. In The molecular biology of the yeast Saccharomyces. Life cycle and inheritence (ed. J.N. Strathern, E.W. Jones, and J.R. Broach), pp. 59-96. Cold Spring Harbor Laboratory, Cold Spring Harbor, New York.

Byers, B. and L. Goetsch. 1973. Duplication of the spindle plaques and integration of the yeast cell cycle. Cold Spring Harbor Symp. Quant. Biol. 38: 123-131.

- 1975. Behavior of the spindle plaques in the cell cycle and conjugation of Saccharomyces ceverisiae. I. Bacteriol. 124: 511-523.

Carle, G. and M. Olson. 1985. An electrophoretic karyotype for yeast. Proc. Natl. Acad. Sci. 82: 3756-3760.

Cohen, C. and D. Parry. 1990. Alpha-helical coiled-coils and bundles: How to design an alpha-helical protein. Proteins, Structure, Funct. Genet. 7: 1-15.

Conde, J. and G.R. Fink. 1976. A mutant of Saccharomyces cerevisiae defective for nuclear fusion. Proc. Natl. Acad. Sci. 73: 3651-3655.

Costigan, C., S. Gehrung, and M. Snyder. 1992. A synthetic lethal screen identifies SLK1, a novel protein kinase homolog implicated in yeast cell morphogenesis and cell growth. Mol. Cell. Biol. 12: 1162-1178.

Cross, F., L.H. Hartwell, C. Jackson, and J.B. Konopka. 1988. Conjugation in Saccharomyces cerevisiae. Annu. Rev. Cell Biol. 4: 429-457.

Delgado, M.A. and J. Conde. 1984. Benomyl prevents nuclear fusion in Saccharomyces cerevisiae. Mol. \& Gen. Genet. 193: $188-189$.

Dolan, J.W., C. Kirkman, and S. Fields. 1989. The yeast STE12 protein binds to the DNA sequence mediating pheromone induction. Proc. Natl. Acad. Sci. 86: 5703-5707.
Dutcher, S.K. and L.H. Hartwell. 1983. Genes that act before conjugation to prepare the Saccharomyces cerevisiae nucleus for caryogamy. Cell 33: 203-210.

Elion, E.A., P.L. Grisafi, and G.R. Fink. 1990. FUS3 encodes a $\mathrm{cdc} 2+/ \mathrm{CDC} 28$-related kinase required for the transition from mitosis into conjugation. Cell 60: 649-664.

Euteneur, U. and J.R. McIntosh. 1981. Structural polarity of kinetochore microtubules in PtKl cells. J. Cell Biol. 89: 338345.

Garnier, I., D.J. Osguthorpe, and B. Robson. 1978. Analysis of the accuracy and implications of simple methods for the predicting the secondary structure of globular proteins. $I$. Mol. Biol. 120: 97-120.

Gehrung, S. and M. Snyder. 1990. The SPA2 gene of Saccharomyces cerevisae is important for pheromone-induced morphogenesis and efficient mating. $J$. Cell Biol. 111: 14511464.

Gerring, S.L., F. Spencer, and P. Hieter. 1990. The CHL1 (CTF1) gene product of Saccharomyces cerevisiae is important for chromsome transmission and normal cell cycle progression in $\mathrm{G}_{2} /$ M. $E M B O$ I. 9: 4347-4358.

Hartwell, L.H. and D. Smith. 1985. Altered fidelity of mitotic chromosome transmission in cell cycle mutants of $\mathrm{S}$. cerevisiae. Genetics 110: 381-395.

Henikoff, S. 1984. Unidirectional digestion with exonuclease III creates targeted breakpoints for DNA sequencing. Gene 28: 351-359.

Hieter, P., C. Mann, M. Snyder, and R.W. Davis. 1985. Mitotic stability of yeast chromosomes: A colony color assay that measures nondisjunction and chromosome loss. Cell 40: 381-392.

Hill, J.E., A.M. Myers, T.J. Koerner, and A. Tzagoloff. 1986. Yeast/ E. coli shuttle vectors with multiple unique restriction sites. Yeast 2: 163-167.

Holm, C., T. Goto, J.C. Wang, and D. Botstein. 1985. DNA topoisomerase II required at the time of mitosis in yeast. Cell 41: 553-563.

Horio, T. and H. Hotani. 1986. Visualization of dynamic instability of individual microtubules by dark-field microscopy. Nature 321: 605-607.

Hoyt, M.A., T. Stearns, and D. Botstein. 1990. Chromosome instability mutants of Saccharomyces cerevisiae that are defective in microtubule-mediated processes. Mol. Cell. Biol. 10: 223-234.

Hoyt, M.A., L. Toti, and B.T. Roberts. 1991. S. cerevisiae genes required for cell cycle arrest in response to loss of microtubule function. Cell 66: 507-517.

Huffaker, T.C., J.H. Thomas, and D. Botstein. 1988. Diverse effects of $\beta$-tubulin mutations on microtubule formation and function. J. Cell Biol. 106: 1997-2010.

Hutter, K.J. and H.E. Eipel. 1978. Flow cytometric determinations of cellular substances in algae, bacteria, molds and yeast. Antonie Leeuwenhoek I. Microbiol. Serol. 44: 269282.

Jacobs, C.W., A.E. M. Adams, P.J. Szaniszlo, and J.R. Pringle. 1988. Functions of microtubules in the Saccharomyces cerevisiae cell cycle. J. Cell Biol. 107: 1409-1426.

Kilmartin, J.V., B. Wright, and C. Milstein. 1982. Rat monoclonal antibodies derived by using a new nonsecreting rat cell line. J. Cell Biol. 93: 576-582.

Kim, J., P.O. Ljungdahl, and G.R. Fink. 1991. kem1- mutations affect nuclear fusion in Saccharomyces cerevisiae. Genetics 126: 799-812.

Kronstad, J.W., J.A. Holly, and V.L. MacKay. 1987. A yeast operator overlaps an upstream activation site. Cell 50: 369377. 
Maniatis, T., E.F. Fritsch, and J. Sambrook. 1982. Molecular cloning: A laboratory manual. Cold Spring Harbor Laboratory, Cold Spring Harbor, New York.

Meluh, P.B. and M.D. Rose. 1990. KAR3, a kinesin-related gene required for yeast nuclear fusion. Cell 60: 1029-1941.

Mirzayan, C., C.S. Copeland, and M. Snyder. 1992. The NUF1 gene encodes an essential coiled-coil related protein that is a potential component of the yeast nucleoskeleton. I. Cell Biol. 116: 1319-1332.

Mitchison, T.J. 1989. Polewards microtubule flux in the mitotic spindle: Evidence from photoactivation of fluorescence. $I$. Cell Biol. 109: 637-652.

Mitchison, T. and M. Kirschner. 1984. Dynamic instability of microtubule growth. Nature 312: 237-242.

Moens, P.B. and E. Rapport. 1971. Spindles, spindle plaques, and meiosis in the yeast Saccharomyces cerevisiae. I. Cell Biol. 50: 344-361.

Neff, N.F., J.H. Thomas, P. Grisafi, and D. Botstein. 1983. Isolation of the $\beta$-tubulin gene from yeast and demonstration of its essential function in vivo. Cell 33: 211-219.

Oakley, B.R. 1992. Gamma-tubulin: The microtubule organizer? Trends Cell Biol. 2: 1-5.

Oakley, B., E. Oakley, Y. Yoon, and M.K. Jung. 1990. Gammatubulin is a component of the spindle pole body that is essential for microtubule function in Aspergillus nidulans. Cell 61: 1289-1301.

Palmer, R.E., E. Hogan, and D. Koshland. 1990. Mitotic transmission of artifical chromosomes in cdc mutants of the yeast, Saccharomyces cerevisiae. Genetics 125: 763-774.

Pearson, W.R. 1990. Rapid and sensitive sequence comparison with FASTP and FASTA. Methods Enzymol. 183: 63-98.

Peterson, J.B. and H. Ris. 1976. Electron-microscopic study of the spindle and chromosome movement in the yeast Saccharomyces cerevisiae. J. Cell Sci. 22: 219-242.

Pillus, L. and F. Solomon. 1986. Components of microtubular structures in Saccharomyces cerevisiae. Proc. Natl. Acad. Sci. 83: 2468-2472.

Poliana, J. and J. Conde. 1982. Genes involved in the control of nuclear fusion during the sexual cycle of Saccharomyces cerevisiae. Mol. \&) Gen. Genet. 186: 253-258.

Rong, L. and A.W. Murray. 1991. Feedback control of mitosis in budding yeast. Cell 66: 519-531.

Rose, M.D. 1991. Nuclear fusion in yeast. Annu. Rev. Microbiol. 45: 539-567.

Rose, M.D. and G.R. Fink. 1987. KAR1, a gene required for function of both intranuclear and extranuclear microtubules in yeast. Cell 48: 1047-1060.

Rose, M.D., B.R. Price, and G.R. Fink. 1986. Saccharomyces cerevisiae nuclear fusion requires prior activation by alpha factor. Mol. Cell. Biol. 6: 3490-3497.

Rose, M., P. Novick, J. Thomas, D. Botstein, and G. Fink. 1987. A Saccharomyces cerevisiae genomic plasmid bank based on a centromere-containing shuttle vector. Gene 60: 237-243.

Rose, M., L.M. Misra, and J.P. Vogel. 1989. KAR2, a karyogamy gene, is the yeast homolog of the mammalian BiP/GRP78 gene. Cell 57: 1211-1221.

Rothstein, R.J. 1983. One-step gene disruption in yeast. Methods Enzymol. 101: 202-211.

Rout, M.P. and J.V. Kilmartin. 1990. Components of the yeast spindle and spindle pole body. I. Cell Biol. 111: 1913-1927.

Sanger, F., S. Nicklen, and A.R. Coulson. 1977. DNA sequencing with chain-terminating inhibitors. Proc. Natl. Acad. Sci. 74: $5463-5467$.

Sherman, F., G.R. Fink, and J.B. Hicks. 1986. Methods in yeast genetics. Cold Spring Harbor Laboratory, Cold Spring Harbor, New York.
Siefert, H.S., M. So, and F. Hefferon. 1986. Shuttle mutagenesis: A method of introducing transposons into transformable organisms. In Genetic engineering: Principles and methods (ed. J.K. Setlow and A. Hollaender), pp. 123-133. Plenum Press, New York.

Sikorski, R. and P. Hieter. 1989. A system of shuttle vectors and yeast host strains designed for efficient manipulation of DNA in Saccharomyces cerevisiae. Genetics 122: 19-27.

Smith, D.B. and K.S. Johnson. 1988. Single-step purification of polypeptides expressed in Escherichia coli as fusions with glutathione S-transferase. Gene 67: 31-40.

Snyder, M. 1989. The SPA2 protein of yeast localizes to sites of cell growth. J. Cell Biol. 108: 1419-1429.

Snyder, M. and R.W. Davis. 1988. SPA1: A gene important for chromosome segregation and other mitotic functions in $\mathrm{S}$. cerevisiae. Cell 54: 743-754.

Snyder, M., S. Gehrung, and B.D. Page. 1991. Temporal and genetic control of cell polarity in Saccharomyces cerevisiae. I. Cell Biol. 114: 515-532.

Spencer, F., C. Connelly, S. Lee, and P. Hieter. 1988. Isolation and cloning of conditionally lethal chromosome transmission fidelity genes in Saccharomyces cerevisiae. Cancer Cells 6: 441-452.

Spencer, F., S.L. Gerring, C. Connelly, and P. Hieter. 1990. Mitotic chromosome transmission fidelity mutants in Saccharomyces cerevisiae. Genetics 124: 237-249.

Stearns, T., M.A. Hoyt, and D. Botstein. 1990. Yeast mutants sensitive to antimicrotubule drugs define three genes that regulate microtubule function. Genetics 124: 251-162.

Telzer, B. and L. Haimo. 1981. Decoration of the spindle microtubules with dynein: Evidence for uniform polarity. $J$. Cell Biol. 89: 373-378.

Trueheart, I., J.D. Boeke, and G.R. Fink. 1987. Two genes required for cell fusion during yeast conjugation: Evidence for a pheromone-induced surface protein. Mol. Cell. Biol. 7: 2316-2328.

Vallen, E.A., T.Y. Scherson, T. Roberts, K.V. Zee, and M.D. Rose. 1992. Asymmetric mitotic segregation of the yeast spindle pole body. Cell 16: 505-515.

Van Arsdell, S.W. and J. Thorner. 1987. Hormonal regulation of gene expression in yeast. In Transcriptional control mechanisms (ed. G.D. Granner, M.G. Rosenfeld, and S. Chang), pp. 325-332. Alan R. Liss, New York.

Weinert, T. and L. Hartwell. 1988. The RAD9 gene controls the cell cycle reponse to DNA damage in Saccharomyces cerevisiae. Nature 241: 317-322.

Winey, M., L. Goetsch, and B. Byers. 1991. MPS1 and MPS2: Novel yeast genes defining distinct steps of spindle pole body duplication. J. Cell. Biol. 114: 745-754. 


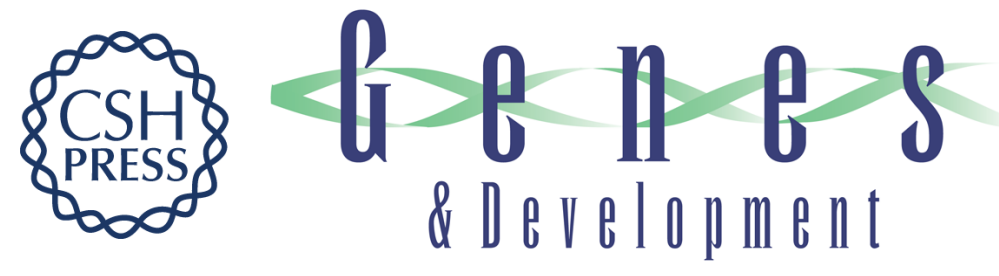

\section{CIK1: a developmentally regulated spindle pole body-associated protein important for microtubule functions in Saccharomyces cerevisiae.}

B D Page and M Snyder

Genes Dev. 1992, 6:

Access the most recent version at doi:10.1101/gad.6.8.1414

References This article cites 71 articles, 34 of which can be accessed free at: http://genesdev.cshlp.org/content/6/8/1414.full.html\#ref-list-1

License

Email Alerting Service

Receive free email alerts when new articles cite this article - sign up in the box at the top right corner of the article or click here.

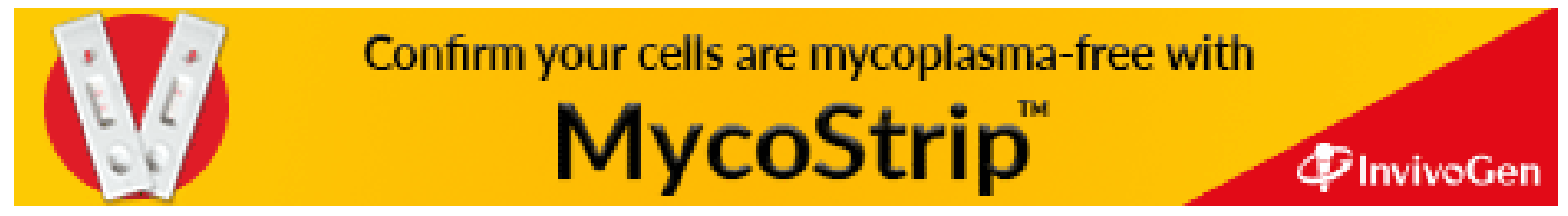

